\title{
EL DEPÓSITO IRREGULAR EN EL DERECHO CHILENO*
}

\section{THE IRREGULAR DEPOSIT IN CHILEAN LAW}

\author{
Alejandro Guzmán Brito**
}

\section{RESUMEN}

El artículo trata del depósito de dinero u otros fungibles, sean consumibles o no, que la tradición medieval denomina "irregular", tratado en el artículo 2221 del $C C$. Después de diferenciarlo del regular, sobre infungibles, se examina su origen romano y algunos puntos de su evolución en la Edad Media para desembocar en la comparación de una docena y media de códigos, en los cuales se percibe cierta variedad de regímenes, aunque se los pueda agrupar según líneas comunes. Se plantea, enseguida, el tema de la naturaleza jurídica del depósito irregular y los principales problemas dogmáticos que él ofrece, lo mismo que el régimen legal al que queda sometido.

Palabras clave: Depósito irregular, depósito de fungibles, crédito.

\section{Abstract}

The article is about the deposit of money or other fungible, whether consumable or not, that the medieval tradition called "irregular", discussed in the article $2221 C C$. After differentiate regular on infungibles, is examined its Roman origins and some points of its evolution in the Middle Ages and the comparison of a dozen or codes, in which is perceived some variety of regimes, although they can be grouped according to common lines. Immediately

* Este artículo hace parte de la investigación que al mismo tiempo concierne al proyecto patrocinado por el Fondo de Investigación Científica y Tecnológica de Chile, bajo el número 1130646, cuyo título es: "Los actos irregulares o anómalos en el Derecho chileno"; y al proyecto Anillo de Investigación Asociativa patrocinado por la Comisión de Investigación Científica y Tecnológica bajo el código SOC 1111: "Estudios dogmáticos de Derecho patrimonial privado".

** Profesor de Derecho Romano, Facultad de Derecho, Pontificia Universidad Católica de Valparaíso. Dirección postal: avenida Brasil No 2950. Valparaíso, Chile. Artículo recibido el 20 de agosto de 2014 y aceptado para su publicación el 3 de octubre de 2014. Correo electrónico: aguzman@ucv.cl 
it raises the issue of the legal nature of the irregular deposit and the main legal problems that he offers, as well as the legal regime to which they are bound.

Keywords: Irregular Deposit, Deposit of fungibles, Credit.

Se denomina "depósito irregular"1 al contrato de depósito que sus partes, sin error ${ }^{2}$ ni simulación y con deliberación, hacen recaer sobre fungibles, sean o no consumibles ${ }^{3}$. La irregularidad estriba en que el depósito debe

${ }^{1}$ Por influencia de Niemeyer (1888), p. 110, n. 21, suele repetirse que el introductor de la denominación “depósito irregular” fue el jurista medieval Jason del Maino (1435-1519). Así, entre otros, Coppa-Zuccari (1901), p. 2; Simone (1952/1993), p. 31 [= traducción de 1956, p. 24]; Micheo (1963), p. 755. Pero hay alguna matización que imponer. El comentarista Paulo de Castro (c. 1360-1441) parece haber sido, en realidad, el primero en decir que el depósito de dinero "habet irregularem naturam depositi" ["tiene naturaleza

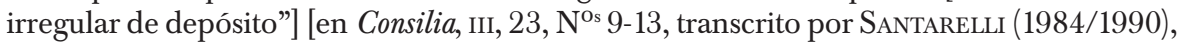
p. 248]. El indicado Jasón del Maino calificaba de "proprius et regularis" al depósito de infungibles (en Lectura in Dig., ad 1. Ai quis nec causam, Dig. Si certum petatur, $\mathrm{N}^{\mathrm{O}} 1$, transcrito por en SANTARELLI (1984/1990), pp. 250-251) y Francesco Mantica (1534-1614) terminó por introducir el adjetivo, al dividir el depósito en "regularis" e "irregularis" (en Vaticinac elucubrationes de tacitis et ambiguis conventionibus, lib. I, tít. $3^{\circ}, \mathrm{N}^{\circ} 10 ;$ lib. X, tít. $2^{\circ}, \mathrm{N}^{\circ} 10$; 88 lib. $\mathrm{x}$, tít. $3^{\circ}, \mathrm{N}^{\mathrm{O}} \mathrm{11}-15$, transcritos por SANTARELLI (1984/1990), pp. 253-254). Desde entonces la terminología entró en el uso común.

${ }^{2} \mathrm{Si}$ hay error, la operación ingresa en el campo de los vicios del consentimiento y, por ende, de la nulidad.

${ }^{3}$ Los conceptos de los incisos $1^{\circ}$ y $2^{\circ}$ del artículo 575 del $C C$, son algo desorientadores, aunque, bien leídos, no del todo inexactos. Las clases de cosas fungibles y no fungibles, por un lado, y de consumibles e inconsumibles, por otro, es mejor mantenerlas separadas. Claro ello, resulta que las fungibles pueden ser consumibles (como un conjunto de frutas) o inconsumibles (como un conjunto de vasos de vidrio). Y, aunque se puede poner ejemplos rebuscados de cosas consumibles no fungibles (como la torta de novios del príncipe de Gales), lo normal es que los consumibles sean fungibles. Ahora bien, es esto último lo que dice el artículo 575 inciso $2^{\circ}$ del $C C$, el cual, en síntesis y en otro lenguaje, manifiesta, en efecto, que las cosas consumibles pertenecen a la clase de las fungibles. Se observará, pues, que esa disposición no dice que las cosas fungibles sean "aquellas de que no puede hacerse el uso conveniente a su naturaleza sin que se destruyan”; y, por ende, ella es inadecuada la crítica que suele dirigirse al artículo $575 \mathrm{del} C C$, según la cual la fungibilidad ahí "aparece confundida con el consumimiento o destrucción de las cosas por el uso natural de ella”. Claro Solar (1930/1992), p. 152. La norma no confunde la fungibilidad con el consumimiento o destrucción de las cosas, ni con la consumibilidad; se limita a decir lo ya apuntado, en orden a que las cosas consumibles pertenecen a las fungibles, lo que es exacto. Por lo demás, el propio autor citado termina por confundirse el mismo cuando escribe: "En la práctica, las cosas que desde luego se presentan como fungibles son las que se consumen por el primer uso [...]", op. cit., p. 156, incurriendo en el error que achaca indebidamente al Código, que no lo comete. En el actual mundo de baratijas industriales cada día más hay cosas fungibles no consumibles. Lo que sí es verdadero, en todo caso, es que el Código no define qué sean las cosas fungibles e infungibles. 
tener por objeto a cosas infungibles e inconsumibles (y entonces se le da el nombre contrario de "regular"); en el entendido de que depositar un cofre,arca, caja o cualquier otro recipiente ${ }^{4}$ en donde se contengan fungibles, pero de tal modo encerrados ahí que no puedan ser extraídas sin fracturar el recipiente, es sin más un depósito del todo regular, porque en tal caso el continente-que es lo depositado-infungibiliza al contenido ${ }^{5}$.

\section{El depósito Regular en el Código CIVIL}

El depósito regular, que el Código identifica con el que denomina "propiamente dicho" en el artículo introductorio 2214 y en la rúbrica del $§ 1$ del título $32^{\circ}$ de su libro IV, es, pues, aquel que tiene por objeto infungibles e inconsumibles.

1. Con todo, esta exigencia de infungibilidad e inconsumibilidad no ha sido formulada de manera directa por la ley; pero sí indirectamente, pues los artículos 2211 y 2215 del $C C$ expresan que la cosa corporal depositada ha de ser restituida "en especie" por el depositario al depositante. Ahora bien, eso que mandan tales disposiciones solo puede ser cumplido si la cosa depositada ya era una especie (o cuerpo cierto) ella misma;y si es así, no pudo tratarse de fungibles ${ }^{6}$. Por lo demás, el artículo 2228 del $C C$ ordena: "El depositario es obligado a la restitución de la misma cosa o cosas individuales que se le han confiado en depósito [...]”. La expresión "cosa o cosas individuales" está por "especie o especies" en la norma.

El artículo 2228 continua así: "aunque consistan en dinero o cosas fungibles; salvo el caso del artículo 2221". Según esto, no bien las cosas depositadas hayan consistido en dinero o cosas fungibles, aun así el depositario debe restituir el "mismo" dinero o los "mismos" fungibles que recibió en guarda. Pero la referencia al artículo 2221 permite comprender el verdadero alcance de la aparente excepción contenida en el artículo

${ }^{4} \mathrm{Si}$ tiene cerradura, basta que se la haya accionado para evitar la apertura y la llave la tenga el depositante, que es un caso ejemplar ofrecido por el propio artículo 2221 del $C C$.

${ }^{5}$ Acaece algo semejante a cuando se legan "las 30 fanegas de trigo que se hallarán en tal parte" (por ejemplo, en el silo $\mathrm{N}^{\circ} 5$ ), que no vale sino con respecto al trigo que se encontrare en el lugar señalado y que no pase de 30 fanegas (art. 1112 inc. final del CC), porque "las 30 fanegas de trigo que se hallaran en tal parte" son cosa infungibles y su legado es, en consecuencia, de especie, no de género. El lugar, lo mismo que el recipiente y otras circunstancias, infungibilizan a una cosa naturalmente fungible, como el trigo.

${ }^{6}$ Cierto es que las nociones de cosa fungible y no fungible no son las mismas que las de cosas genéricas y especificas; como, empero, sí es cierto que las cosas fungibles se designan de forma genérica y de manera específica las infungibles, en la práctica resultan co-incidentes. Es por tal razón que, en el lenguaje del Código, el término 'especie' (o cuerpo cierto) mienta una cosa infungible (desde luego designada específicamente). 
2228: se trata de dinero o fungibles colocados en arca cerrada cuya llave tiene el depositante o con otras precauciones que hagan imposible tomarlos sin fractura. En tal caso, dice el último artículo citado, el depositario debe restituir el recipiente intacto que encierra el dinero o los fungibles -porque el artículo 2223 del $C C$ dispone que la obligación de guardar la cosa depositada comprende la de respetar los sellos y cerraduras del bulto que la contiene-, salvo que se haya configurado un deposito irregular por no haber envase cerrado.

2. Dogmática, ya no legislativamente, la exigencia de infungibilidad e inconsumibilidad en la cosa depositada en realidad deriva de la configuración del depósito como contrato no traslaticio de dominio y de mera tenencia sin aprovechamiento de uso, disfrute ni disposición.

Que el depósito sea un contrato, no traslaticio de dominio sino de mera tenencia se deduce del artículo 714 del $C C$ que, aunque no menciona al depositario, sí menciona al secuestre como mero tenedor. Ahora bien, dado que el secuestre es un depositario más vigoroso que el depositario propiamente tal, se sigue que este último a fortiori es también un mero tenedor.

En lo que respecta al uso, el artículo 2220 inciso $1^{\circ}$ del $C C$ establece que, por el mero depósito, no se confiere al depositante la facultad de usar la cosa depositada.

90 En lo concerniente al disfrute, el artículo 2229 del CC ordena que la cosa depositada deba restituirse con sus frutos, los cuales, por ende, o no pertenecen al depositario o los debe, y es por ello que debe restituirlos?.

$\mathrm{Y}$ en lo tocante a la disposición, sea material, sea jurídica, un acto deliberado de dicha significación necesariamente sería doloso o culpable de culpa lata o grave, que equivale al dolo (art. 44 inc. $2^{\circ}$ del $C C$ ), lo cual tornaría en responsable al depositario (art. 2222 inc. $2^{\circ}$ del $C C$ ); y esto es índice de que merced al contrato tal acto no le compete ${ }^{8}$.

3. En un concreto depósito, empero, el depositante puede conferir permiso de usar la cosa al depositario. Es una posibilidad tratada por el artículo 2220 inciso $1^{\circ}$ del $C C$, que no aclara si en tal caso el contrato se convierte en comodato, cuando lo depositado son especies no fungibles, o si persevera en su naturaleza de depósito, modificado con la facultad de

${ }^{7}$ Como de hecho lo normal es que los frutos consistan en cosas fungibles y hasta consumibles (como dinero o frutas), ellos pertenecerán al depositario, aunque deba restituirlos sin poder, por ende, lucrarlos.

${ }^{8}$ La consumición fortuita de la cosa, como si la pieza de cristal depositada y esmeradamente guarecida se destruye, pese a todo, por causa de un terremoto, y la consumición no imputable a la culpa grave del depositario, como si la misma pieza se destruye por un traspié del que la trasladaba con todo cuidado y precaución, sufrido cuando una rata se le atravesó en su camino, no son actos de consumición permitidos al depositario, sino accidentes acaecidos a la cosa depositada de los que aquel no responde. 
usar $^{9}$. Es más correcto concluir esto último, porque el artículo $2222 \mathrm{~N}^{\circ} 2$ del $C C$ establece que el depositario responde de la culpa leve si tiene interés personal en el depósito, de lo cual es ejemplo legal que se le haya permitido usar la cosa en ciertos casos. Ahora bien, si entonces el contrato cambiara a comodato, la responsabilidad del autorizado para usar la cosa tendría que llegar a la culpa levísima, como, en materia de ese contrato, dispone el artículo 2178 inciso $1^{\circ}$ del $C C$. Que el contrato mantenga su naturaleza de depósito se explica porque en él no se ausenta la función de guarda y custodia que en este último contrato constituye el interés del depositante, y solo se le agrega el permiso de usar, que ahora, por cierto, interesa al depositario, con lo cual la operación empieza a pertenecer a la categoría de las que se celebran para beneficio recíproco de las partes. Pero en ellas se responde precisamente de la culpa leve (art. 1547 del CC).

La ley no trata el caso de que el depositante autorizare a lucrar los frutos de la cosa en custodia al depositario; pero es evidente que tal figura, de suyo lícita y legalmente posible, implicaría una donación de los frutos.

En fin, nos resta el caso de que el depositante autorizare la disposición de la cosa en guarda al depositario. A priori podemos concluir que eso no es posible, porque tal implicaría transferir su dominio al depositario, y el depósito dejaría de ser un contrato de mera tenencia de la cosa sin su aprovechamiento; en otras palabras, la entrega que constituye el negocio importaría una tradición y el convenio de depósito, un título traslaticio de dominio. Pero como con esta hipótesis ya empezamos a adentrarnos en el campo propio al cual se destina el presente trabajo, dejaremos hasta aquí el punto por el momento.

4. Ahora bien, si el depósito pudiere tener por objetivo cosas fungibles o consumibles, el depositante no podría controlar que la cosa que se le restituye es la misma que depositó; ni que el depositario se limitó a tenerla sin aprovecharla de otro modo, como exige la ley. El depositario, en efecto, podría disponer, física o jurídicamente, las cosas recibidas en custodia y después reponerlas con otras especies distintas, aunque del mismo género y calidad a aquellas y restituirlas en la misma cantidad al depositante. En tal caso, las disposiciones legales destinadas a configurar al depósito como un contrato de mera tenencia sin aprovechamiento y sin adquisición de la propiedad ni de la posesión serían nada más que meras declaraciones de un derecho ilusorio y fantástico sin posibilidad alguna de verdadera aplicación.

${ }^{9}$ En el caso del depósito mercantil, que puede ser oneroso, vale decir, con remuneración para el depositario (art. 809 del CCom.), el permiso de usar la cosa lo mudaría a un arrendamiento de ésta. Si fuera civil, que es gratuito y se convierte en arrendamiento de servicios si es con remuneración (art. 2219 del CC), el permiso de usar la cosa lo cambiaria también a arrendamiento de esa cosa. 


\title{
II. El Depósito irRegular en el Código CiVIL
}

1. Con todo, en el interior del título $2^{\circ}$ : "Del depósito" del libro IV del $C C$., su artículo 2221 dispone:

\begin{abstract}
"En el depósito de dinero, si no es en arca cerrada cuya llave tiene el depositante, o con otras precauciones que hagan imposible tomarlo sin fractura, se presumirá que se permite emplearlo, y el depositario será obligado a restituir otro tanto en la misma moneda”.
\end{abstract}

La norma, pues, contradice por completo la doctrina que venimos de exponer en orden a la infungibilidad e inconsumibilidad del objeto del depósito, pues regula un "depósito de dinero" y habla de un "depositario" con referencia a aquel. De paso, comentemos algo preanunciado, en orden a que la deposición de dinero en arca cerrada con llave, que conserva el depositante, o con otras precauciones que hagan imposible tomar sin fractura el dinero, no contiene la aludida contradicción y es verdadero y normal depósito (regular). Esta figura no constituye el tema del artículo 2221 del CC. La hipótesis del mismo es que se deposite dinero constante, vale decir, que se entreguen billetes o monedas físicamente en descubierto 92 por uno que entiende ser su depositante a otro que entiende recibirlas como depositario. Si tal es el caso, dice la norma, se presumirá que se permite emplear el dinero al depositario; lo cual significa que este puede disponerlo de manera física, como destruirlo, o desde el punto de vista jurídico, como gastarlo. En todo caso -añade la disposición- el depositario contrae la obligación de restituir otro tanto en la misma moneda, es decir, la misma cantidad de dinero que le fue entregada. Aunque la norma presuma el permiso de emplear el dinero, la obligación de restituir otro tanto es independiente de que se haya hecho o no uso de tal autorización. Esto es así porque, tratándose de un fungible absoluto como es el dinero, nunca resulta posible conocer si el dinero devuelto sea el mismo que el entregado o que no lo sea. Si el depositario, pues, empleó el dinero recibido o si no lo empleó, eso aparece como una situación privada suya, que no influye en los efectos de la operación.

2. El dispositivo del artículo $2221 \mathrm{del} C C$ se entiende bien en el contexto en que aparece localizado, vale decir, a continuación del artículo 2220 CCch.:

“[Inciso $1^{\circ}$ ] Por el mero depósito no se confiere al depositario la facultad de usar la cosa depositada sin el permiso del depositante./ [Inciso $2^{\circ}$ ] Este permiso podrá a veces presumirse, y queda al arbitrio del juez calificar las circunstancias que justifiquen la 
presunción, como las relaciones de amistad y confianza entre las partes./ [Inciso $3^{\circ}$ ] Se presume más fácilmente este permiso en las cosas que no se deterioran sensiblemente por el uso".

En síntesis, la norma viene a decir que el depositante puede dar su permiso al depositario, para usar la cosa depositada; que tal permiso puede ser expreso o presumido por un juez; en cuyo arbitrio queda calificar si los hechos justifican o no una presunción de permiso de empleo de la cosa en custodia dado por el depositante al depositario; y que, no obstante, cuando lo depositado son cosas que no se deterioran por su uso, el juez puede hacer la presunción de permiso con menos exigencias ("más fácilmente") que sí pueden deteriorarse por esta razón ${ }^{10}$.

Sobre estas bases sentadas por el artículo 2221 del $C C$ el siguiente dispone que "en el depósito de dinero" se presuma estar permitido emplearlo por el depositario. Aunque la norma al parecer contiene una orden dada al juez de presumirun permiso él mismo, en realidad más que de una presunción judicial parece tratarse de una simplemente legal: el depositario está eximido de probar que se le confirió un permiso de empleo y toca al depositante demostrar que no lo confirió o que prohibió el empleo del dinero; a falta de esta última prueba, el juez ha de decidir que hubo permiso.

De la presunción de permiso de empleo del dinero depositado, la ley extrae la natural consecuencia de que, con independencia de su efectivo empleo, el depositario está obligado a devolver otro tanto del dinero recibido.

3. Atendida la estructura legal de la noción de depósito de dinero que acabamos de considerar, cabe indagar las consecuencias de que el depositante destruya la presunción legal de permiso de uso de aquel. Si el depositante, en efecto, lograra demostrar que, por ejemplo, prohibió el empleo del dinero, ¿que se seguiría de ello? Creemos que nada diferente al estado sujeto a la presunción; vale decir, igual podría el depositario emplear el dinero, o sea, por ejemplo, gastarlo o destruirlo, y después reponerlo, restituyendo otro tanto del mismo recibido. El depositante no tendría cómo demostrar que este último es otro dinero que el entregado, a menos que lo hubiera desfungibilizado, por ejemplo, anotando la serie individual de cada billete (lo cual equivaldría a la consideración legal de haber guardado el dinero en arca cerrada cuya llave conserve el depositante, o con otras precauciones que hagan imposible tomarlo sin fractura), en el cual caso ya estaríamos fuera del ámbito que constituye el objeto propio de la regulación del artículo 2221 del $C C$.

${ }^{10}$ Obsérvese que la ley no habla de las cosas consumibles, sino de las que suelen denominarse "deteriorables" o que se desgastan poco a poco en la medida de su uso a través del tiempo, como los zapatos o la ropa en general. En rigor estas cosas son inconsumibles, porque subsisten después de su primer uso natural, y es solo por su uso reiterado que se corrompen. 
La anterior observación nos permite criticar la dicción legal concerniente a la presunción: si se trata de dinero depositado, da exactamente lo mismo que se conceda o no permiso para su empleo; y entonces la presunción de autorización de tal empleo es inútil y superflua. Pero veremos pronto que la idea de un permiso proviene de la historia del dogma y ha perseverado en las codificaciones.

4. En fin, cabe observar que la letra del artículo 2221 del $C C$ atañe solo al depósito de dinero; no, pues, al depósito de fungibles en general. Pero que ese artículo se extiende a toda clase de fungibles (sean o no consumibles) es apoyado desde luego por la analogía que permite la extensión fundada en la identidad de la razón que rige al dicho artículo y a una norma que dijera lo mismo que él con reemplazo de "dinero" por "fungibles" y "en la misma moneda" por "del mismo género y calidad", con las debidas adaptaciones gramaticales derivadas del número ${ }^{11}$.

Dicha extensión, además, se ve apoyada por el dispositivo del artículo 2228 del $C C$ :

"El depositario es obligado a la restitución de la misma cosa o cosas individuales que se le han confiado en depósito, aunque consistan en dinero o cosas fungibles; salvo el caso del artículo 2221".

La norma hace referencia a "cosas que consistan en dinero o cosas fungibles", que si fueron depositadas deben ser devueltas las mismas; pero impone la excepción del artículo 2221; lo cual significa que, cuando se depositó dinero o cosas fungibles no en arca cerrada cuya llave tenga el depositante, ni con otras precauciones que hagan imposible tomarese dinero o cosas fungibles sin fractura del arca, entonces el depositario quedará en los términos de la última frase del citado artículo. Ahora bien, todo este discurre sobre la base de solo el depósito "de dinero"; mientras que el artículo 2228 lo hace sobre la base del depósito "de dinero o de cosas fungibles"; y entonces una de dos: o el artículo 2221 es inaplicable a la hipótesis del artículo 2228 pese a la remisión expresa de este a aquel en orden a aplicarlo; o es aplicable; y en este último caso, el artículo 2221 hay que entenderlo también referido a las cosas fungibles, aunque no sean dinero.

Tal conclusión es, por cierto, la correcta; y, de acuerdo con ella, sin mayor dificultad entenderemos el dispositivo del artículo 2221 del $C C$ como referido no solo al dinero, al que literalmente atañe, sino a las cosas fungibles en general -incluido desde luego el dinero que es un tipo de las mismas-, porque ellas están contenidas en el sentido de la citada disposición.

11 ‘Tomarlo' por ‘tomarlos' y ‘emplearlo' por 'emplearlos'. 
III. EL ORIGEN DE LA FIGURA DEL DEPÓSITO LLAMADO IRREGULAR

1. El depósito de cosas fungibles e inconsumibles es una figura que los juristas romanos conocieron muy bien y de la cual dejaron no pocos testimonios en sus escritos ${ }^{12}$. La romanística hipercrítica de la primera mitad del siglo xx, empero, pensaba que esa figura había sido un invento bizantino, del Derecho posclásico o del justinianeo en consecuencia, y que los textos de los Iustiniani Digesta en que comparece habían sido intervenidos y no eran, por ende, clásicos. A lo más se llegó a admitir que en la última época clásica un jurista tan tardío como Papiniano había conocido el depósito irregular. Hoy no adoptamos un punto de vista tan drástico y pensamos que los clásicos aceptaban la figura.

La primera referencia que tenemos a ella aparece en Dig. 19,2,31, en un texto atribuido al jurista republicano Alfeno Varo (que el año 39 a. C. fue cónsul suffectus ${ }^{13}$ ) extraído del libro v de sus Digesta epitomados por Paulo. El pasaje que interesa pertenece a un contexto en que se habla del caso de varios que contrataron el transporte de su trigo en cierta nave de un tal Saufeius, en cuya bodega fue almacenado el trigo de todos, de modo de quedar confundido el conjunto en una masa común. En circunstancias de que el armador devolvió a uno su parte del trigo y después naufragó la nave, se pregunta por la acción disponible para los demás en función de recuperar lo entregado originalmente. La respuesta de Alfeno parte con la afirmación de haber dos géneros de cosas dadas en arrendamiento (respondit rerum locatarum duo genera esse): para que se devuelva lo mismo, como cuando se entregan vestimentas al lavandero para que las lave; o para que se devuelva una cosa del mismo género, como cuando se entrega plata refinada u oro a un artífice para que fabrique unos vasos o unos anillos. Se entiende, pues, que, en el primer caso, hay que devolver los mismos vestidos, de modo que estos permanecen en el dominio del que los entregó; y que en el segundo, en cambio, los vasos o los anillos pudieron ser fabricados con plata u oro distintos, con tal que se los haya fabricado con uno u otro metal, así que el originalmente entregado en realidad queda constituido en crédito (in creditum iri), es decir, se hace del que lo recibió,

${ }^{12}$ La literatura más antigua sobre el depósito irregular en el Derecho Romano es esta: Longo (1906), pp. 121-156; Longo (1964), pp. 59-81; SEgrè (1907), pp. 197-234; Bonifacio (1948), pp. 80-152; Seidl (1951), tomo I, pp. 373-379. La más moderna, esta otra: Brasiello (1956), pp. 475-503; Adams (1962), pp. 360-371; Michel (1962), pp. 75-95; Hannu (1969); Gandolfi (1976), pp. 148 y ss. y 178 y ss.; LitewsKi (1974), pp. 215-262; LiTEWSKI (1975), pp. 279-315; GORDON (1982), tomo III, pp. 363-372; ViGNERON (1984), pp. 307-324; Herrera Bravo (1987), pp. 389-418; Churruca (1991), en especial pp. 315-324; Valmaña Ochaíta (1996).

${ }^{13}$ Se denominaba consul suffectus al elegido como suplente del titular que falleció. 
de guisa que quien lo entregó es solo su acreedor ${ }^{14}$. En el texto se sostiene que este mismo derecho rige en el depósito (Idem iuris esse in deposito) pues:

"[...] si quis pecuniam numeratam ita deposuisset, ut neque clausam neque obsignatam traderet, sed adnumeraret, nihil alius eum debere apud quem deposita esset, nisi tantundem pecunia esolveret".
"[...] si alguno hubiera depositado monedas no encerradas ni selladas, sino merced a su entrega contadas una a una, aquel a quien le hubieran sido depositadas nada más debe que no sea pagar otro tanto de dinero".

Se puede agitar la cuestión de si este discurso sobre el depósito pertenece a Alfeno ${ }^{15}$, el autor original de los Digesta, o a Paulo, quien epitomó, abrevió o resumió esa obra de Alfeno (y al cual epítome pertenece el pasaje); o, incluso, a un anónimo maestro postclásico, que habría añadido el íntegro texto relativo al depósito en las márgenes de la parte correspondiente de un ejemplar del epítome, que en algún momento editorial posterior habría ingresado en el cuerpo mismo de esa obra y llegado a los compiladores de los Digesta de Justiniano, donde hoy lo leemos. Como ya hicimos notar, la romanística hipercrítica del siglo pasado más bien se inclinó por pensar en el origen bizantino de nuestra figura y por explicaciones del tipo de la hipótesis precedente, en aplicación de un método que ya no aceptamos. Creemos que se trata de una auténtica opinión de Alfeno ${ }^{16}$.

${ }^{14}$ Dig. 19,2 31 (Alf., 5 dig. a Paulo epit.): "In navem Saufeii cum complures frumentum confuderant, Saufeius uni ex his frumentum reddiderat de communi et navis perierat: quaesitum est, an ceteri pro sua parte frumenti cum nauta agere possunt oneris aversi actione. Respondit rerum locatarum duo genera esse, ut auti dem redderetur (sicuti cum vestimenta fulloni curanda locarentur) aute iusdem generis redderetur (veluti cum argentum pusulatum fabro daretur, ut vasa fierent, aut aurum, ut anuli): ex superiore causa rem domini manere, ex posteriore in creditum iri. [...]" ("Como muchos hubieran confundido su trigo en la nave de Saufeio, éste hubiera devuelto del común su trigo a uno de aquéllos y la nave pereciera, se preguntó si acaso los demás pueden demandar por su cuota al navegante con la acción de retiro de la carga. Respondí que hay dos géneros de cosas arrendadas, o para que se devuelva lo mismo (como cuando se dan en arrendamiento vestimentas al lavandero para que las lave), o para que se devuelva cosa del mismo género (como cuando se diese plata acrisolada al artífice para que hiciere vasos u oro para anillos): en el primer caso, la cosa permanece en el [primitivo] dueño; en el segundo va a crédito [...]”).

${ }^{15} \mathrm{O}$ a Servio Sulpicio Rufo, el maestro de Alfeno, ya que hay textos de éste en que, sin mención expresa del maestro, se reproducen opiniones suyas; véase KRÜGER (1912), p. 71; pero no existen indicios que permitan la sospecha de ser el caso de Dig. 19,2,31.

${ }^{16}$ Uno de los puntos de crítica era que en la frase "nisi tantundem pecuniae solveret" no es admisible este último verbo. Por ello algunos enmendaron "solveret" por "solvere et", y así la frase entera "nihil alius eum debere apud quem deposita esset, nisi tantun dempecuniae" queda "aquel a quien le hubieran sido depositadas nada más debe que no sea pagar otro tanto de dinero; y". De este modo queda restablecida la secuencia latina en infinitivo "debere [...] solvere". Se trata de un discurso indirecto que en último término depende de "respondit" ("respondió") (de donde los infinitivos "debere" y "solvere"); y 
Lo que sí puede causar legítima extrañeza es la inserción de un discurso sobre el depósito en otro sobre el arrendamiento. Pero la inicial sorpresa desaparece si pensamos en que había novedad en el régimen de la locatio conductio y no en aquel del depósito, de modo que cuanto se expresa sobre este es a modo de argumento en favor de la solución que se da para el caso del arrendamiento. En otras palabras, la idea de que en algún arrendamiento se entrega una cosa para que se devuelva, no la misma, sino otra del mismo género va apoyada en cuanto acaece en el depósito de dinero no especificado. Si es así, eso demuestra que para Alfeno la figura del depósito de dinero y su régimen eran algo tan consolidado, que admitía ser invocado como precedente ${ }^{17}$.

Lo cual tal vez no deba extrañar, si tenemos presente que el uso de un depósito de dinero, incluso con intereses, fue practicado de manera profusa en el mundo helenístico ${ }^{18}$, de donde seguramente lo tomó la práctica romana.

2. El examen de las fuentes sobre nuestra materia nos enseña que los juristas distinguían varias situaciones:

- La primera es la del depósito de dinero contenido en un arca cerrada, que, sin más,es considerado como un verdadero depósito del arca, deja obligado al depositario a restituirla cerrada y no le permite disponer del dinero (so pena del hurto) ${ }^{19}$.

- La segunda es la del depósito de dinero especificado (por ejemplo, en un arca cerrada), cuyo depositante después permite el uso (o sea, el consumo) del dinero al depositario. Nerva y Próculo, después Marcelo y finalmente Ulpiano, pensaron que la operación es desde el principio un mutuo, de modo que el tradente dispone de la actio condictio para recuperar el dinero, como acaece en todo mutuo ${ }^{20}$.

En fin, cuando se entrega dinero especificado con permiso de usarlo dado al comienzo (o sea, desde la entrega), la operación es un depósito ${ }^{21}$,

el que responde es Alfeno, no Paulo. Un maestro glosador postclásico difícilmente se hubiera ocupado de construir una frase suya, exterior al texto original, en estilo indirecto.

${ }^{17}$ Sobre este contexto de la discusión suscitada por Alfeno, véase Petrucci (1991), pp. 128-131.

${ }^{18}$ Véanse: Mitteis (1898), No 6, pp. 208-212; KÜBleR (1908), pp. 189-215; FrEZZA (1956), pp. 139-172; PolaY (1962), pp. 82-85; KLAMI (1986), pp. 89-100; Roth (1970); SimON (1965), pp. 39-66.

${ }_{19}$ Dig. 16,3,29pr.; 19,2,31.

${ }^{20}$ Dig. 12,1,9,9 (Ulp., 26 ed.). Aunque el texto no lo dice, podemos entender que el consentimiento mutuario sustituyó al consentimiento depositario, cuando el que entregó permitió el uso del dinero al que recibió y este aceptó el permiso (expresa o tácitamente). El texto añade que hay mutuo con independencia de que se use las monedas. Pero no dice que el dinero entregado iba especificado. Ahora bien, no se entendería el texto si no fuera así. En especial carecería de sentido la afirmación de que el riesgo del dinero pasa al que lo había recibido, pues es inexplicable que, de no haber estado especificado el dinero, aunque no haya habido permiso para usarlo, el riesgo fuera del que lo entregó.

${ }^{21}$ Dig. $16,3,1,34 ; 12,1,10$. 
sancionada con la actiodepositi in ius con la cual se puede cobrar intereses por el perjuicio causado y desde luego por la mora en devolverlos ${ }^{22}$.

La operación que los juristas romanos consideraron como un depósito no fue designada como "irregular" por ellos. Tal denominación es medie$\mathrm{val}^{23}$. Pero estaban conscientes de constituir una anomalía. Al respecto, se nos conserva un pasaje de Papiniano en Dig. 16,3,24 (9 quaest.), que reza así:

“'LuciusTitiusSemproniosalutem.Centum nummos, quos hac die commendasti mihi adnumerante servo Sticho actore, esse apud me ut notum haberes, hace pistula manu mea scripta tibi notum facio: quae quandovoles et ubi voles confestim tibi numerabo'. Quaeritur propter usurarum incrementum. Respondi depositi actionem locum habere: quid est enim aliud commendare quam deponere? Quod itaverum est, si id actum est, ut corpora nummorum eadem redderentur; nam si ut tantundem solveretur convenit, egreditur ea res depositi notissimos terminos. In qua quaestione si depositi actio non teneat, cum convenit tantundem, non idem reddi, rationem usurarum haberi non facile dicendum est. Et est quidem constitutum in bonae fidei iudiciis, quod ad usuras attinet ut tantundem possit officium arbitri quantum stipulatio; sed contra bonam fidem et depositi naturam est usuras ab eo desiderare temporis ante moram, qui beneficium in suscipienda pecunia dedit. Si tamen ab initio de usuris praestandis convenit, lex contractus servabitur".
"Lucio Ticio saluda a Sempronio. Por medio de esta carta escrita de mi mano te hago saber, para que lo tengas entendido, que las cien monedas que en este día me has encomendado merced a la entrega hecha por el esclavo Estico, [tu] administrador, están en mi poder, las cuales te devolveré inmediatamente cuándo y dónde quieras', Se pregunta por el incremento a título de intereses. Respondí que tiene lugar la acción del depósito, porque, ¿qué otra cosa es encomendar sino que depositar? Lo cual es verdad en este sentido, si se actuó para que se devolvieran los mismos cuerpos físicos de las monedas; pues si se convino que se pagara otro tanto, la operación sale de los conocidísimos límites del depósito. En cuyo caso, si la acción del depósito no obligue cuando se haya convenido devolver, no lo mismo, sino otro tanto, no se ha de decir fácilmente que deba tenerse cuenta de los intereses. Y se encuentra firmemente establecido que en los juicios de buena fe, por lo que a los intereses atañe, tanto pueda el oficio del árbitro cuanto la estipulación; pero es contrario a la buena fe y a la naturaleza del depósito reclamar intereses por el tiempo anterior a la mora del que hizo un beneficio al recibir el dinero. Si, empero, se convino el pagode intereses desde el comienzo, se observará la ley del contrato"

${ }^{22}$ Dig. 16,3,29,1; 16,3,28; 16,3,24; 16,3,25,1. Cuando se entrega dinero no especificado y desde el principio (o después) se permite su uso, hay mutuo aunque se diga tratarse de un depósito (Pauli Sent. 2,12,9 = Collatio 10,7,9).

${ }^{23}$ Véase la n. 1. 
Papiniano $^{24}$ absuelve una quaestio que realmente le fue sometida, sobre la base de una carta escrita de puño y letra y a modo de "recibo" por alguien (Lucio Ticio), al que le habían sido entregadas cien monedas por otro (Sempronio), a través de un esclavo administrador de este último. El firmante reconoce que la operación consistió en "encomendarle dinero"("nummos, quos commendasti mihi") y que ahora tiene en su poder; y ofrece, seguramente repitiendo los términos declarados por el esclavo al momento de la entrega del dinero, devolverlo cuando el encomendador quiera y dónde quiera. Este último consultó a Papiniano sobre la posibilidad de exigir intereses al encomendado.

Para responder, el jurista se basa en el vocablo 'encomendar' ('commendare') empleado por las partes para definir la operación; y, atendido que 'encomendar' significa no otra cosa que 'depositar', concluye que aquella consistió precisamente en un depósito; de lo cual se sigue que deba tener lugar la acción del depósito (actiodepositi). Claro que tales así siempre y cuando lo actuado por las partes haya consistido en convenir que se devolviera las mismas monedas (corpora nummorum eadem) entregadas; porque si lo acordado fue que se pagara nada más que el mismo tanto de dinero (tantumdem), entonces el negocio excede o traspasa los límites o términos del depósito, que son muy conocidos por todos (egrediturea res depositinotissimos términos). Con esta frase, el jurista elude una respuesta directa; y a partir de eso evita asumir un compromiso. Sus puntos son los siguientes:

i) Si se considera no aplicable la actiodepositi cuando se haya convenido devolver, no lo mismo, sino otro tanto, difícilmente se puede hacer cuenta de los intereses;

ii) Si se considera aplicable dicha acción, que es de buena fe, constituye un principio muy firme que en tal género de acciones el oficio del juez pueda ordenar el pago de intereses tanto como si se los hubiera fijado en una estipulación formal;

iii) En todo caso, es contra la buena fe y la naturaleza del depósito reclamar intereses por el tiempo anterior a la mora del depositario; $y$

iv) Cuando se hubiera acordado el pago de intereses desde el inicio, o sea, desde la entrega del dinero, se estará a lo acordado, vale decir, se los podrá exigir desde aquel momento, y no solo desde la mora, hasta su devolución.

Como puede apreciarse, el pasaje contiene las cuestiones fundamentales del depósito que llamamos irregular. Pero en este momento nos interesa destacar lo que dice Papiniano en orden a considerar que la operación de entregar un tanto de dinero para la que se acuerda la devolución, no

${ }^{24}$ Sobre este pasaje, además de la literatura general citada en la n. 12, véase también Petrucci (1991), pp. 220-224. 
del mismo dinero físico entregado, sino de otro tanto idéntico (con otras monedas físicas, por ende), está fuera de los límites del depósito. Esto no puede dejar de significar que tal operación no es un depósito ${ }^{25}$.

Para terminar esta exposición sobre el pensamiento de los juristas romanos acerca de nuestra materia, hagamos notar que todos los textos relativos a ella discurren sobre la base de depósito de dinero y que no los hay sobre depósito de otros fungibles.

\section{Algunos PUntos SOBRE El DEPÓSito IRREgUlar en el Derecho Común}

1. No podemos detenernos demasiado sobre la manera en que los juristas medievales enfrentaron las fuentes romanas acerca del depósito de dinero $^{26}$; así que nos fijaremos en algunos destacables aspectos suyos.

${ }^{25}$ Existe un texto de Paulo en Dig. 16,3,26,1 (4 respon.), que contiene la respuesta de ese jurista a una consulta sobre la posibilidad de cobrar los intereses en el depósito de una cantidad de dinero, que habían sido expresa y detalladamente pactados. El jurista dice: "[...] cum contractum, de quo quaeritur, depositae pecuniae modum excedere" ("[...] 100 como el contrato acerca del cual se pregunta excede la medida del dinero depositado"); y concluye: "et ideo secundum conventionem usurae quoque actione depositi peti possunt" (“y por esto según la convención los intereses también pueden ser pedidos con la acción del depósito"). El razonamiento expuesto es casi imposible de ser entendido con certeza, porque no se sabe qué mienta la palabra "medida" ("modum"), que, aplicada al dinero depositado, el contrato excedería; y porque se huele una contradicción entre la premisa de que el contrato excede la medida del dinero depositado y la conclusión de que se puede pedir los intereses con la acción del depósito, de modo de esperarse que, merced a tal exceso, los intereses no se podrían exigir. Para los diferentes problemas que ofrece el texto, véase Valmaña Ochaita (1996), pp. 98-105. Es interesante lo que conjetura Niemeyer (1888), en orden a que el negocio que Paulo tuvo históricamente a la vista no se diferenciaría del foenus nauticum, para el cual, como es sabido, no había límites al monto de los intereses. En un contexto así se explicaría que, pese a que el contrato del caso excedía el "depositae pecuniae modum", el jurista respondiera que se pueden cobrar los intereses. Solo que el texto habla de un "exceso del dinero depositado", no de un "exceso del interés pactado". Fuere como haya sido, el estado actual del texto no permite conseguir muchas conclusiones firmes. Pero es seguro, a mi juicio, que la frase "depositae pecuniae modum excedere" del texto nada tiene que ver con la frase "egreditur ea res depositi notissimos términos" de Dig. 16.3.24, como a veces se ha solido decir, así Coppa-ZucCARI (1901), p. 3.

${ }^{26}$ Para la historia del depósito irregular fuera del Derecho Romano Niemeyer (1888), pp. 111-118; Coppa-ZucCari (1901), pp. 32-60; Micheo (1963), pp. 756-757; Garrigues y Diaz-CAÑábate (1932), Nº 87, pp. 161-173; N 88, pp. 241-256 y Nº 89, pp. 321-336; Astuti (1964), No 6, pp. 232-235. El libro histórico de SANTARELLI (1984/1990), aunque dedicado a la categoría general de la "irregularidad", discurre sobre todo acerca del depósito irregular (y en especial de él en pp. 67-104). Para la historia del depósito irregular en el derecho español: MarTínez Gijón (1964), $\mathrm{N}^{\text {os }}$ 9-15, pp. 80-128. 
Desde luego cabe poner en relieve que dichos juristas ampliaron la consideración del depósito de dinero, único al cual se habían limitado los textos romanos, al de fungibles. Ya el glosador Azo ( $\uparrow$ c. 1229) se había referido, en efecto al depósito de aquello "quod est in pondere, numero vel mensura", con referencia mental a los fungibles ${ }^{27}$. También cabe insistir en algo ya advertido, respecto a que fueron juristas de la última Edad Media quienes usaron el adjetivo 'irregular' para dar nombre al depósito de fungibles ${ }^{28}$.

Por otro lado, también los medievales fueron quienes plantearon la cuestión fundamental que hubo de agitarse en siglos posteriores, en orden a si el depósito de fungibles es un verdadero depósito o un mutuo.

Para Azo, pese a que el depósito de fungibles transfiere el dominio al depositario, es, empero, un depósito. Una postura más matizada sostuvo Accursius (1182/1185-1260/1263): la entrega de fungibles en depósito con autorización expresa de usarlos dada al principio constituye mutuo sin más, a menos que las partes acuerden que quieren la permanencia del negocio en un depósito; pero la entrega de fungibles en depósito con autorización tácita de usarlos concedida al principio deja al negocio en depósito y no transita a mutuo. Ahora bien, se presume la autorización para el uso de los fungibles cuando se entregan sin más y cuando se conviene que el depositario deba devolver el tantumdem. Accursius, pues, hace depender el tipo de negocio celebrado de la voluntad expresa o tácita de las partes.

Sus ideas determinaron la doctrina de los tiempos posteriores. Así lo vemos, por ejemplo, en el comentario al Digestum Vetum de Iacobus Butrigarius (c. 1274-1348). Para la mejor comprensión del complejo texto suyo que hemos escogido, procederemos a descomponerlo y a numerar sus diferentes partes:

Si deponatur pecunia, quando constituatur depositum et quando mutuum: "Circa hanc materiam distingui, quia: I. aut agitur, quod sit mutuum vel depositum, et illud servatur;

II. aut hoc non est declaratum; et tunc

$1^{\circ}$ aut datur potestas utendi expresse; et tunc:

i) aut ab initio commodo et non est mutuum antequam utaris, ii) aut ex post facto do potestatem utendi et tunc statim sit mutuum;
Si se deponga dinero, cuándo se constituya un depósito y cuándo un mutuo: "Acerca de esta materia distingue, porque: I. o se trata de que haya un mutuo o un depósito, y tal es lo que se observa; II. o no se declara ni lo uno ni lo otro; y entonces:

$1^{\circ}$ o se da expresamente la potestad de usar; y est vez:

i) o bien desde el comienzo doy en comodato y no hay mutuo antes de que uses, ii) o doy después la potestad de usar y entonces hay mutuo de inmediato;

${ }^{27}$ Azo 1506/1966), lib. IV, "Depositi", fol. 143.

${ }^{28}$ Véase la n. 1. 
$2^{\circ}$ aut cedo potestatem utendi tacite id, quod est, cum do pecuniam ad tenendum; tunc est depositum contra suam naturam [...];

$3^{\circ}$ aut non conceditur expressa potestas utendi nec tacita, ut cum datur pecunia signata, et tunc est depositum [...] nec depositarius uti potesteo, imofurtum committeret.

Et prodest multum scire propter usuras, quae aliter veniunt in bonae fidei iudiciis et aliter in stricti iuris iudiciis"*. $2^{\circ}$ o cedo tácitamente la potestad de usar, lo cual acaece cuando doy dinero para que se lo tenga; entonces es depósito aun en contra de su naturaleza[...]; $3^{\circ}$ o la potestad de usar no se concede expresa ni tácitamente, como cuando se entrega dinero individualizado, y entonces es depósito [...] y el depositario no puede usarlo, pues de lo contrario comete hurto. Y es muy útil conocer estas cosas en razón de los intereses, porque estos son tratados de una manera en los juicios de buena fe y de otra en los juicios de derecho estricto".

Iacobus Butrigarius comienza sus explicaciones con una distinción suprema: al entregar dinero una parte a otra o, bien,

I. dijeron que celebraban, ora un mutuo ora un depósito y la conclusión es que hay que observar lo declarado, de guisa que el negocio es, pues, un mutuo o un depósito; o, bien,

II. nada dijeron al respecto. Para este segundo caso, nuestro jurista subdistingue tres posibilidades:

$1^{\circ}$ Si se dio de forma expresa la potestad de usar el dinero;

102

$2^{\circ}$ Si se dio tácitamente la potestad de usarlo;

$3^{\circ}$ Si no se otorgo de forma expresa o tácita dicha potestad.

En la hipótesis $1^{\mathrm{a}}$, de haberse dado expresamente la potestad de usar el dinero, es necesario volver a distinguir si:

i) se la dio en este supuesto al principio del negocio y Iacobus Butrigarius señala que no hay mutuo antes de ejercer la facultad de usar sobreentendiendo que sí lo hay desde que se ejerce. En realidad esto lo dice en segundo término, porque antes había declarado: "doy en comodato" (commodo), lo que no viene al caso en un discurso en que se supone la entrega de dinero que en ningún caso puede constituir comodato; a menos que haya pasado sin aviso a otra hipótesis: que se entregó un recipiente cerrado con dinero en su interior. Si al principio se da la facultad de usar el dinero, antes de usarlo efectivamente, para el autor habría comodato del recipiente y después, mutuo del dinero;

ii) Si la facultad de usar se dio con posterioridad a la celebración del acto, hay mutuo de inmediato, vale decir, desde que se dio tal facultad y antes de ejercerla de hecho.

En la hipótesis $2^{\mathrm{a}}$, de haberse concedido tácitamente la facultad de usar el dinero, hay depósito, aunque ello sea contrario a la verdadera naturaleza de este contrato.

*Butriagus (1606), pp. 180-181, ad lib. XIII, tít. $3^{\text {o: }: ~ " D e p o s i t i v ~ e l ~ c o n t r a ", ~ l e y ~} 25^{\mathrm{a}}, \S$ "Quipecuniam". 
En la $3^{\mathrm{a}}$ hipótesis, de no haberse conferido expresa ni tácitamente la facultad de usar el dinero, el depositario no puede usarlo porque cometería hurto, a condición de que el dinero se haya entregado individualizado, porque entonces hay verdadero depósito.

El texto termina con una explicación concerniente a la importancia de saber si hay mutuo o depósito, debido a que la acción del mutuo es de derecho estricto y la del depósito de buena fe; en el entendido que con la primera no se puede exigir intereses, aunque se los haya pactado; mientras que con la segunda se los puede exigir, no obstante no se los haya pactado.

\section{El DEPÓSITO IRREGULAR EN LA CODIFICACIÓN}

1. Examinaremos ahora las posturas asumidas por las codificaciones modernas ante el depósito irregular.

a) Conviene empezar con el examen del Código Civil bávaro de 1756, que, empero, ya no rige. El $\S 8$ del capítulo $2^{\circ}$ de su $4^{\text {a }}$ parte expresaba:

"Depositum irregulare kann sich zwar $1^{\circ}$ auf unterschiedliche Art, insonderheit aber $2^{\circ}$ daraus ergeben, wenn res fungibilis deponirt, und annebens Depositario der Gebrauch entweder ausdrücklich oder stillschweigend eingeräumt wird, dann da nimmt das Depositum die Natur eines Darlehens an sich, und wird nicht erst von Zeit des wircklichen Gebrauchs, sondern gleich von Zeit der Übergab durchgehens hiernach beurteilt. Auf stillschweigende Weise pflegt man $3^{\circ}$ den Gebrauch einzuräumen, wenn z[um] E. [xempel] gezähltes Geld unverschlossener deponirt wird, welches jedoch auch wiederum seines Absatz leidet, wenn die deponirte Summa nicht in Current, sondern in Schatzgeld bestehet, oder wenigstens Restitutio in eadem Specie daher versprochen wird".
"El 'depósito irregular' puede resultar $1^{\circ}$ de diferentes maneras, pero especialmente $2^{\circ}$ cuando se depositan 'cosas fungibles' y se concede expresa o tácitamente su uso al 'depositario', pues entonces el 'depósito' toma para sí la naturaleza de un mutuo, y [como tal] es considerado no solo desde el momento del uso efectivo, sino desde el momento de la entrega en adelante. De manera tácita suele concederse el uso $3^{\circ}$ cuando, p.[or] e.[jemplo], se deposita dinero al contado y no encerrado, el cual, sin embargo, también sufre consumo si la 'suma' depositada consiste no en dinero corriente sino en metálico, o al menos si se ha prometido la 'restitución' de la misma "especie".

Pese al anuncio de existir varias maneras de celebrar un depósito irregular -y es digno de observarse este uso del nombre que el ius commune había terminado por imponer a la operación-, este cuerpo legal reconoce de forma fundamental una: el depósito de cosas fungibles con autorización dada expresa o tácitamente al depositario para usarlas; en el entendido de que hay autorización tácita si lo depositado es dinero (la principal de 
las cosas fungibles) no encerrado en algún recipiente o si se promete la restitución ineodemgenus ${ }^{29}$. Ahora bien, si se da la autorización de uso, el depósito deja de ser tal y transita a mutuo, y se lo considera así desde el momento de la entrega constitutiva de la operación (que es real), no, pues, desde el momento en que el favorecido hizo uso de las cosas. Esto implica que para el Código bávaro, en rigor, el "depósito" irregular no es undepósito sino precisamente un mutuo.

b) El Código prusiano de 1794 tampoco está en actual vigencia, pero es interesante su manera de acercarse al tema. La materia en examen aparece tratada en el título $14^{\circ}$, sección $1^{\mathrm{a}}$ de la $1^{\mathrm{a}}$ parte, entre los $\S \S 80$ y 88 . Tal regulación comienza con prohibir al depositario tanto el uso propio de la cosa que custodia como la concesión de un permiso a terceros para que la usen $(\S 80)^{30}$, en la cual no se incluye el uso necesario para la conservación de la cosa (§ 81). El $\S 82$ establece que no se cambia la naturaleza de este contrato cuando el depositante permite expresamente un uso inocente ("un schädlichen Gebrauch") de la cosa bajo determinadas circunstancias al depositario. Después de formuladas estas prohibiciones y sus aclaraciones, el $\S 83$ advierte que, con todo, desde el momento en que el depositario empieza a ejercer la autorización de uso inocente, el negocio transita a un préstamo si se trata de cosas fungibles, o a un comodato o arrendamiento 104 si se trata de otras $\operatorname{cosas}^{31}$. Esto explica que el $\S 82$ tuviera previsto, como

${ }^{29} \mathrm{El} \S 8$ dice “eadem species”; pero es claro que el término 'species' está aquí por 'genus'; de lo contrario no se entendería. Se trata del depósito irregular de dinero: si lo acordado es que se devuelva el mismo dinero depositado, no es irregular; pero si lo convenido es que se restituya otro dinero del mismo género, sí lo es.

${ }^{30} \mathrm{El} \S 87$ sanciona el uso no autorizado de la cosa depositada con la obligación de restituir todos los beneficios conseguidos con ese uso y de responder por los accidentes que la deterioren o causen su pérdida. Cfr. el $\S 86$ para otra modalidad de indemnización.

${ }^{31} A L P S, 1^{\mathrm{a}}$ parte, tít. $14^{\circ} \mathrm{sec}, 1^{\mathrm{a}}, \S 83$ : "Sobald aber der Verwahrer sich dieser Erlaubniß zu bedienen anfängt, so geht das Geschäft, bey verbrauchbaren Sachen in einen Darlehns, und bey andern in einen Leih-oder Mietvertrag über". La idea de que el uso autorizado de la cosa depositada hace cambiar la naturaleza del negocio según sea la clase de cosa de que se trate: a mutuo, si se trata de fungibles, o a comodato en el caso contrario se la ve, por ejemplo, en Domat (1735), lib. I, tít. $7^{\circ}$, sec. $1^{\mathrm{a}}, \S 10$, tomo I, p. 78: si se concede al depositario la facultad de servirse de la cosa depositada, mientras no ejerza esta facultad es un depositario; pero desde el momento en que la ejerza la figura cambia su naturaleza y queda sujeta a las reglas del préstamo de uso (comodato) si "es una cosa que permanece en [su] naturaleza" ("si c'est une chosequidemeure en nature"), o a aquellas del préstamo (mutuo) si es tal que al usarla cesa de tenerla (“cesse de l'avoir”). Pero, como se ve, Jean Domat, piensa en términos de consumibilidad y no en términos de fungibilidad. En todo caso, él no se plantea la hipótesis de que deba haber una mudanza a arrendamiento, cuando la cosa es infungible y el depósito era remunerado. La alternativa de mutuo o comodato es también la que ofrece Heineccius (1773), § 810, p. 438. En cambio, Wolf (1744), vol. IV, $\S 610$, pp. 417-418 piensa en otra alternativa: mutuo, si la cosa fungible es 
vimos, que por la sola autorización de uso no muda la naturaleza del depósito, porque ello solo acaece con el efectivo uso.

La alternativa de conversión a comodato o a arrendamiento depende de si el depósito fue gratuito o remunerado, posibilidad está última expresamente prevista en el $\S 84$. Es consecuente que si no hubo remuneración, el depósito mude a comodato, pero a arrendamiento si la hubo.

El $\S 84$ contiene una interesante norma: si a alguien se le ha confiado (se entiende que en depósito) dinero efectivo, títulos de crédito u otras cosas consumibles, pero con autorización para tenerlas como si se le hubieran dados en mutuo, la ley restringe el uso que el depositario pueda hacer de semejante autorización, porque la operación, aunque le haya sido atribuida el nombre de "depósito", tan pronto como el depositario empiece a hacer uso de la autorización es mirada como un mutuo hecho en fraude a la ley ${ }^{32}$.

El $§ 87$ se sitúa en la hipótesis de un depósito de dinero de manera implícita distingue dos posibilidades:

i) que se haya concedido el uso del dinero al depositario, caso en el cual se supone aplicable el $\S 83$ y el negocio transita a mutuo desde que se ejerce la autorización de uso;

ii) que no se le haya sido concedido ésta, hipótesis en la cual el depositario debe pagar los más altos intereses que el depositante pueda exigir, y a contar del momento mismo del depósito, vale decir, no desde el momento del uso efectivo ${ }^{33}$; y en tal caso el depositario debe ser juzgado en consideración al lugar de donde es la moneda o, en defecto, según las reglas del mutuo $(\S 88)^{34}$.

Este conjunto de minuciosas normas está lejos de resplandecer por su claridad. Pero, en lo que se puede ver, parece que ahí se dice que:

recibida con autorización de usarla; o promesa de mutuo, si es recibida para que la use cuando sea el caso de necesitarla. Wolf (1763), §539, p. 278, en cambio, dice que cuando el depositante concede el uso de la cosa al depositario, el depósito se mezcla ("miscetur") con un comodato (cuando recae sobre infungibles, aunque no lo diga expresamente) o con un mutuo, si se trata de dinero.

${ }^{32}$ ALPS, § 84: "Wenn baare Gelder, geldgleiche Papiere, oder andere verbrauchbare Sachen jemanden, welcher in der Befugnis Darlehnsverträge zu schließen, durch die Gesetze eingeschränkt ist, mit der Erlaubniß, sich derselben bedienen zu dürfen, anvertraut worden: so ist das Geschäft, wenn gleich demselben der Name eines Verwahrungsvertrags beigelegt worden, dennoch, sobald der Empfänger von dieser Erlaubniß Gebrauch macht, für ein zur Vereitelung der Gesetze geschlossenes Darlehn zu achten".

${ }^{33} A L P S, \S 87$ : "Hat der Verwahrer die bey ihm niedergelegten Baarschaften, oder andere verbrauchbare Sachen, ohne Erlaubniß genutzt: so muß er, von dem Zeitpunkte der Niederlegung an, die höchsten Zinsen, welche der Niederleger nach seinem Stande fordern kann, entrichten".

${ }^{34}$ ALPS, § 88: "Übrigens ist in einem solchen Falle der Verwahrer in Ansehung der Münzsorten, und sonst, nach den Regeln des Darlehnsvertrages zu beurtheilen". 
i) el depositario no puede usar la cosa depositada y si la usa incurre en responsabilidades;

ii) el depositante puede permitirle un uso inocente de la cosa;

iii) pero en este caso el contrato muda a comodato si el depósito había sido acordado como gratuito; o a arrendamiento, si aquel tenía alguna remuneración;

iv) depositar dinero efectivo u otras cosas consumibles puede ser considerado como un mutuo en fraude a la ley;

v) o si no, el depositante puede autorizar su uso al depositario; quien, si usa tales cosas sin autorización, queda obligado a pagar los más altos intereses posibles;

vi) en ambos casos la operación es mirada como mutuo. En síntesis, pues, el $A L P S$ no acepta la posibilidad de un depósito irregular, que sin más es un mutuo.

c) De los más antiguos cuerpos legales, el Code Civil de 1804 sigue en vigencia. En él leemos el siguiente artículo 1932:

"[Inciso $\left.1^{\circ}\right]$ Le dépositaire doit rendre identiquement la chose même qu'il a reçue./[Inciso $2^{\circ}$ ] Ainsi, le dépôt des sommes monnayées doit être rendu dans les mêmes espèces qu'il a été fait, soit dans le cas d'augmentation, soit dans le cas de diminution de leur valeur".

El inciso $1^{\circ}$, pues, declara que el contrato obliga a devolver la misma cosa recibida. Para el inciso $2^{\circ}$ esta regla sigue plenamente válida aunque lo depositado haya consistido en monedas, pues en tal caso el depositario debe restituir las mismas especies amonedadas que recibió en depósito, aunque su valor entretanto hubiera aumentado o disminuido. Según esto resulta que el Código francés ignora la posibilidad del depósito irregular; este simplemente no existe, de guisa que el depósito de dinero es regular. La doctrina no le ha hecho mucho caso y califica la figura como mutuo ${ }^{35}$.

d) El próximo cuerpo legal que debemos considerar es el Código Civil de Austria: el $A B G B$, emitido en 1811 y también todavía en vigencia. Teniendo presente que, según su $§ 968$, el contrato de depósito no confiere al depositario la propiedad, ni el dominio ni un derecho de uso sobre la cosa; y que aquel es un mero tenedor con la obligación de asegurar que la cosa confiada no sufra daños ${ }^{36}$, el $\S 959$ dice:

${ }^{35}$ En ese sentido pueden verse, entre muchos otros: LAURENT (1893), tomo XXVII, $\mathrm{N}^{\text {os }_{\mathrm{s}}} 72$ 73, pp. 90-93; BaUdry-LaCANTINERIE-WAHL (1907) $\mathrm{N}^{\text {os }}$ 1.092-1.094, pp. 592-593; TroplonG

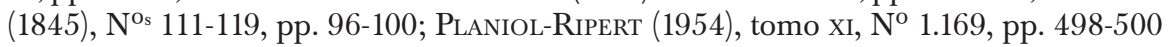

${ }^{36} A B G B .$, § 968: "Durch den Verwahrungsvertrag erwirbt der Uebernehmer weder Eigenthum, noch Besitz, noch Gebrauchsrecht; er ist bloßer Inhaber mit der Pflicht, die ihm anvertraute Sache vor Schaden zusichern". 
"Wird dem Verwahrer auf sein Verlangen, oder durch freiwilliges Anerbieten des Hinterlegers der Gebrauch gestattet; so hört im ersten Falle der Vertrag gleich nach der Verwilligung; im zweiten aber von dem Augenblicke, da das Anerbieten angenommen, oder von der hinterlegten Sache wirklich Gebrauch gemacht worden ist, auf, ein Verwahrungsvertrag zu sein; er wird bei verbrauchbaren Sachen in einen Darlehens-, bei unverbrauchbaren in einen Leihvertrag umgeändert, und es treten die damit verbundenen Rechte und Pflichten ein".
"Si es que queda permitido el uso [de la cosa] al depositario, sea a petición suya, sea por libre ofrecimiento del depositante, el contrato cesa de ser un depósito, desde la convención [misma] en el primer caso, pero desde el momento en que la petición es aceptada o desde que realmente se ha hecho uso de la cosa depositada en el segundo; tratándose de cosas fungibles, aquél se transforma en un mutuo; y de cosas no fungibles, en un comodato; $y$ [entonces] tienen lugar los derechos y obligaciones correspondientes a uno u otro".

Puede que el depositario tenga permiso de usar la cosa depositada, bien que aquel lo hubiera impetrado al depositante, bien que este se lo hubiera ofrecido unilateralmente. En cualquier caso, el contrato cesa de ser un depósito; pero desde un diferente momento. Si el depositario pidió la facultad de usar la cosa y el depositante accedió, como es entonces que se forma un consenso pertinente, desde ese momento cesa de haber depósito. Si, por el contario, el depositante ofreció la facultad de usar la cosa al depositario, la nueva convención se perfecciona en el instante en que éste último aceptó. Ahora bien, tal aceptación puede ser expresa, y entonces la cesación se produce con la aceptación de esa clase; pero también pudo ser tacita, es decir, consistente en que el depositario empiece a usar la cosa y entonces tal será el momento de la convención, desde el cual cesa de haber depósito. Por ello el $\S 959$, para el caso de ofrecimiento unilateral del depositante, dice que "el contrato cesa de ser un depósito [...] desde el momento en que la petición es aceptada o desde que realmente se ha hecho uso de la cosa depositada".

Agrega la disposición que si el original depósito había versado sobre fungibles, con el permiso de su uso se convierte en mutuo; y si, por el contario, sobre infungibles, la mudanza que genera tal permiso es a comodato; y entonces la operación se rige por las reglas del primero de los contratos mencionados o por la del segundo. Obsérvese que la aplicación del estatuto de uno u otro no es con efecto retroactivo al comienzo del negocio original, vale decir, del depósito, sino desde la formación del consentimiento sobre el permiso merced al cual se produce la mudanza; lo dice expresa y directamente el parágrafo: "el contrato cesa de ser un depósito, desde la convención [...], pero desde el momento en [...] o desde [...]".

En síntesis, pues, para el $A B G B$., el permiso de usar las cosas depositadas extingue el depósito y lo convierte en comodato, si aquellas eran 
fungibles; o en mutuo, en el caso contrario. Sin tal permiso, el depositario no puede usar las cosas, sean infungibles o fungibles; y si las usa, todos los daños que ellas sufran y que no hubieran acaecido si estuvieran en manos del depositante, se le imputan sin que pueda poder alegar caso fortuito ${ }^{37}$. e)Entretanto, en 1869 fue emitido un Código Civil en Argentina, que dio un vuelco completo a la materia, pues su artículo 2188 dispuso:

"El depósito voluntario es regular o irregular./ Es regular:/ $1^{\circ}$ Cuando la cosa depositada fuere inmueble, o mueble no consumible, aunque el depositante hubiere concedido al depositario el uso de ella; $/ 2^{\circ}$ Cuando fuere dinero, o una cantidad de cosas consumibles, si el depositante las entregó al depositario en saco o caja cerrada con llave, no entregándole ésta; o fuere un bulto sellado, o con algún signo que lo distinga; $/ 3^{\circ}$ Cuando representase el título de un crédito de dinero, o de cantidad de cosas consumibles, si el depositante no hubiere autorizado al depositario para la cobranza; $4^{\circ}$ Cuando representase el título de un derecho real, o un crédito que no sea de dinero".

En complemento necesario, el artículo 2189 añadió:

"Es irregular:/ $1^{\circ}$ Cuando la cosa depositada fuere dinero, o una cantidad de cosas consumibles, si el depositante concede al depositario el uso de ellas o se las entrega sin las precauciones del artículo anterior, número $2^{\circ}$, aunque no le concediere tal uso y aunque se lo prohibiere; $2^{\circ}$ Cuando representare crédito de dinero, o de cantidad de cosas consumibles, si el depositante autorizó al depositario para su cobranza”.

En primer lugar, destacamos que el término 'irregular', que había comparecido en el muy antiguo Código bávaro de 1756, pero que había desaparecido en los sucesivos, reaparece, casi cien años después, en el Código argentino, el cual, además, habla de "depósito regular", lo que no había acaecido en el bávaro. El primero distingue formalmente entre un depósito voluntario regular y otro irregular. El de inmuebles es siempre regular; también lo es el de títulos de crédito bien de dinero, bien de cantidades de consumibles, si no quedó autorizado su cobro al depositario; y, asimismo, lo es el depósito de títulos de derechos reales o créditos no dinerarios. En fin, es depósito regular el de dinero o consumibles encerrados o sellados, en que el continente y no el contenido es el objeto del depósito.

${ }^{37}$ ABGB., §965: "Hat aber der Verwahrer von der hinterlegten Sache Gebrauch gemacht, [...] und die Sache leidet einen Schaden, welchem sie bei dem Hinterleger nicht ausgesetzt gewesen wäre; so kann er keinen Zufall vorschützen und die Beschädigung wird ihm zugerechnet”. 
Por el contrario, es irregular el depósito de dinero o de consumibles no encerrados ni sellados (sin que interese entonces si autorizó o no el uso ni, incluso, si lo prohibió) o, en el caso contrario, con autorización de usar lo depositado; también lo es el depósito de títulos de crédito de dinero o de otros consumibles si el depositario quedó autorizado para su cobranza.

Dámaso Vélez Sarsfield, el autor del Código argentino, en contra de su costumbre no dejó testimonio de las fuentes que empleó para redactar los artículos 2188 y 2189 del $C C$ arg. ${ }^{38}$.

En todo caso, se observará que para este cuerpo legal el depósito irregular es un tipo de depósito, pues nada dice sobre la posibilidad de su tránsito a mutuo (o comodato o arrendamiento). Al revés, regula los efectos del depósito irregular con toda independencia de los de otros tipos negociales.

Las reglas que establece para el depósito irregular son las siguientes:

i) la cosa depositada se hace del dominio del depositario(art. 2191);

ii) este queda obligado a pagar otro tanto de dinero o cosas consumibles, con tal que sean del mismo género (art. 2220, que dice, empero: "de la misma especie", con un error que ya habíamos observado en el Código bávaro);

iii) cuando es relevante si hubo autorización para usar la cosa depositada, el artículo 2221 permite presumir que la hubo si no consta que el depositante lo prohibió;

iv) si lo hubiere prohibido y el depositario usó las cosas y se constituyó en mora de restituirlas, debe intereses desde el día del depósito.

f) Con el siguiente examen, volvemos a Europa, pues ahora se trata del Código Civil español de 1889. Su artículo 1767 establece la siguiente regla general: "[Inciso $1^{\circ}$ ] El depositario no puede servirse de la cosa depositada sin permiso expreso del depositante./ [Inciso $2^{\circ}$ ]En caso contrario, responderá de los daños y perjuicios".

Sobre tal base, dispone el artículo 1768:

"Cuando el depositario tiene permiso para servirse o usar de la cosa depositada, el contrato pierde el concepto de depósito y se convierte en préstamo o comodato. El permiso no se presume, debiendo probarse su existencia”.

El artículo, con algunas variaciones, proviene del artículo 1671 del Proyecto de Código Civil de 1851, principalmente redactado por Florencio García Goyena. Decía la norma ahí proyectada:

${ }^{38}$ Es tan solo a propósito del artículo 2220 que Dámaso Vélez escribe: "Sobre las diferencias del depósito irregular y el préstamo, Troplong, $\mathrm{N}^{\circ} 117$ ”, con referencia a Troplong (1845), $\mathrm{N}^{\mathrm{O}} 117$, pp. 99-100, donde, en efecto, ese autor explica las diferencias a que remite Dámaso Vélez. 


\begin{abstract}
“[Inciso $1^{\circ}$ ] Cuando el depositario tiene permiso para servirse o usar de la cosa depositada, el contrato cambia de naturaleza, y ya no es depósito sino préstamo o comodato/ [Inciso $2^{\circ}$ ] No se presumirá concedido este permiso en ningún caso, si no consta expresamente”.
\end{abstract}

En su comentario al artículo 1671, Florencio García G. dice haberlo basado en el $\$ 959$ del $A B G B$, pero que lo ha reforzado con el inciso $2^{\circ}$, destinado a apoyar mejor el artículo 1670 (=1677 del CCesp.), donde se establece que el depositario no puede servirse de la cosa depositada sin permiso expreso del depositante y que en caso contrario responderá de los daños e intereses. A propósito de ese artículo 1670, el autor, después de una serie de consideraciones, había concluido: "Desterramos, pues, el depósito irregular"

g) El Código Civilalemán (Bürgerliches Gesetzbuch) de 1896/1900 dedicó un $\S 700$ a nuestra materia, que en su actual redacción, impuesta por la reforma de 2002, reza así:

"Unregelmäßiger Verwahrungsvertrag./ (1) Werden vertretbare Sachen in der Art hinterlegt, dass das Eigentum auf den Verwahrer übergehen und dieser verpflichtet sein soll, Sachen von gleicher Art, Güte und Menge zurückzugewähren, so finden bei Geld die Vorschriften über den Darlehensvertrag, bei anderen Sachen die Vorschriften über den Sachdarlehensvertrag Anwendung. Gestattet der Hinterleger dem Verwahrer, hinterlegte vertretbare Sachen zu verbrauchen, so finden bei Geld die Vorschriften über den Darlehensvertrag, bei anderen Sachen die Vorschriften über den Sachdarlehensvertrag von dem Zeitpunkt an Anwendung, in welchem der Verwahrer sich die Sachen aneignet. In beiden Fällen bestimmen sich jedoch Zeit und Ort der Rückgabe im Zweifel nach den Vorschriften über den Verwahrungsvertrag./ (2) Bei der Hinterlegung von Wertpapieren ist eine Vereinbarung der im Absatz 1 bezeichneten Art nur gültig, wenn sie ausdrücklich getroffen wird".
"Contrato de depósito irregular./ (1) Cuando se deponen cosas fungibles de manera que la propiedad transite al depositario y éste deba quedar obligado a devolver cosas de la mismaclase, calidad y cantidad, tratándose de dinero resultan aplicables las prescripciones sobre el contrato de mutuo de dinero ["Darlehensvertrag"] y tratándose de otras cosas [fungibles], las prescripciones sobre el contrato de mutuo de cosas ["Sachdarlehensvertrag"]. Si el depositante permite consumir las cosas fungibles al depositario, tratándose de dinero resultan aplicables las prescripciones sobre el contrato de mutuo de dinero ["Darlehensvertrag"] y tratándose de otras cosas[fungibles], las prescripciones sobre el contrato de mutuo de cosas ["Sachdarlehensvertrag"] desde el momento en que el depositario se apropie de las cosas. En ambos casos, estando en duda el momento y el lugar de la devolución, se determinarán, sin embargo, según las prescripciones del contrato de depósito./ (2) En el depósito de títulos-valor, un acuerdo del tipo designado en el inciso $1^{\circ}$ es válido solo si ha sido expresamente alcanzado".

${ }^{39}$ García Goyena (1852), tomo IV, p. 90. 
El $B G B$., pues, distingue dos hipótesis ${ }^{40}$ :

$1^{\text {a }}$ La del depósito de fungibles bajo convenio ${ }^{41}$ de que la propiedad transite al depositario y éste deba quedar obligado a devolver cosas de la misma clase, calidad y cantidad, de la cual se distinguen dos subhipótesis:

i) silos fungibles depositados consisten en dinero, la operación se rige por las reglas del mutuo de dinero ("Darlehensvertrag"), definido en el $\S 488$ del $B G B$;

ii) si talesfungibles no consisten dinero, la operación se rige por las reglas del mutuo de fungibles que no sean dinero("Sachdarlehensvertrag") a que se refiere el $\S 607 \mathrm{del} B G B^{42}$;

$2^{\text {a }}$ La del depósito de fungibles bajo permiso ${ }^{43}$ de consumirlos dado al depositario, acerca de la cual vuelve a distinguirse:

i) si los fungibles depositados consisten en dinero, la operación se rige por las reglas del mutuo de dinero ("Darlehensvertrag"), tratado en el $\S 488$ del $B G B$;

ii) si tales fungibles no consisten en dinero, la operación se rige por las reglas del mutuo de fungibles que no sean dinero "Sachdarlehensvertrag" a que se refiere el $\S 607$ del $B G B^{44}$.

${ }^{40}$ Sobre el $§ 700$ del $B G B$, véase Schmoeckel y otros (eds.) (2013), §§ 688-700, II, 8 (sobre el texto anterior a la reforma de 2002) y III, 8 (sobre el texto derivado de la reforma de 2002), pp. 1855 y 1861-1862, respectivamente.

${ }^{41}$ El texto del § 700 no cita ningún convenio y se limita a hablar de unas cosas que "son depositadas de manera" que la propiedad transite al depositario y que éste deba ser obligado a devolver cosas de la misma clase, calidad y cantidad; pero depositarlas de esa manera supone un acuerdo en tal sentido. Así EnNECCERus (1950), § 168, p. 378, dice: "Si en el depósito de cosas fungibles se estipula la transmisión de la propiedad y el que recibe está obligado a devolver cosas de igual especie y cantidad [...]”. Por lo demás, el inciso $2^{\circ}$ del $\S 700$ se remite de manera expresa al "acuerdo" ("Vereinbarung") del tipo indicado en el inciso $1^{\circ}$, acuerdo que no puede ser otro que el de trasmitir la propiedad de los fungibles depositados y devolver otro tanto de su mismo género, y el de poder consumirlos, que, como se ve, son dos, aunque el inciso $2^{\circ}$ esté redactado en singular; a falta de toda especificación, entendemos que el inciso $2^{\circ}$ se refiere a ambos, como ccorrectamente entiende EnNECCERUs (1950), § 168, p. 379, quien, con referencia al inciso $2^{\circ}$, escribe: “[...] el convenio en virtud del cual se transfiere la propiedad [...] o en virtud del cual se autoriza al depositario para consumir [...]"; es decir, entiende que la referencia es a dos convenios.

${ }^{42} \mathrm{El} B G B$ reformado en 2002, pues, distingue dos clases de mutuos: el de dinero (“Darlehensvertrag") y el de otros fungibles ("Sachdarlehensvertrag"); y los trata en sedes sistemáticas diferentes. El texto anterior a la reforma, en cambio, aunque hacía la distinción, los regulaba de forma conjunta en los $\$ \S 607-610$ (que, pues, hablaban de préstamo de dinero o de otras cosas fungibles). El Código Civil de Chile, en el tít. $31^{\circ}$ de su libro IV, disciplina únicamente un préstamo de fungibles, en el entendido de que el dinero pertenece a tal tipo de cosas. El dinero solo aparecía mencionado de forma expresa en el hoy derogado artículo 2199. Subsiste su mención negativa en el artículo 2198 (relativo al préstamo de cosas fungibles que no sean dinero).

${ }^{43}$ También aquí se trata de un acuerdo; véase la n. 39.

${ }^{44}$ La principal diferencia entre uno y otro contrato radica en que el mutuo de dinero está sometido al pago de intereses anuales (“Zinsen”: $§ 488$ inc. $2^{\circ}$ ), mientras que el mutuo 
La aplicabilidad del régimen del mutuo de dinero o del mutuo de otras cosas fungibles procede, no desde el momento en que se concedió el permiso de consumir, sino desde aquel en que el depositario se apropió de las cosas, lo que debe entenderse como desde el momento en que empezó a consumirlas. Si restare una duda acerca del tiempo o el lugar de la restitución, se estará a las reglas dadas para el depósito. El inciso $2^{\circ}$ hace aplicable al depósito de valores los convenios de transferir su propiedad al depositario y de disponerlos, siempre que se establezcan expresamente. Lo cual indica que los mismos convenios en cuanto aplicados a dinero u otras cosas corporales pueden ser tácitos.

h) El Code Civil suizo de 1907/1912 presenta un artículo 481-B sobre nuestro tema:

"Dépôt irrégulier./1. S’il a été convenu expressément ou tacitement que le dépositaire d'une somme d'argent serait tenu de restituer, non les mêmes espèces,mais seulement la même somme, il en a les profits et les risques./2. Une convention tacite se présume, dans le sens indiqué, si la somme a été remise non scellée et non close./3/ Lorsque le dépôt consiste en d'autres choses fongi-
Depósito irregular./ 1. Si se ha convenido expresa o tácitamente que el depositario de una suma de dinero está obligado a restituir, no las mismas especies, sino solamente la misma suma, le pertenecen los provechos y los riesgos./ 2. Si la suma se entregó no cerrada ni sellada, se presume una convención tácita en el sentido indicado./ 3. Cuando el depósito consiste en otras cosas fungibles o en títulos-valores, el depositario no tiene derecho de disponerlos más que cuando haya sido expresamente autorizado por el depositante".

La disposición distingue dos supuestos:

$1^{\circ}$ el depósito de dinero y

$2^{\circ}$ el depósito de otros fungibles distintos al dinero, o de títulos-valores.

En el primer caso, pudo acaecer que:

a) el dinero se haya entregadono encerrado ni sellado, entonces la ley presume esta convención tácita ${ }^{45}$ : que el depositario queda obligado a restituir, no las mismas especies dinerarias recibidas, sino solo su misma cantidad;

b) que el dinero se haya entregado encerrado o sellado, entonces puede

i) convenirse expresa o tácitamente que el depositario quede obligado a restituir, no las mismas especies dinerarias recibidas, sino tan solo su misma cantidad;

ii) no convenirse nada al respecto.

de otros fungibles, solo al pago de una remuneración (“Darlehensentgelts": $§ 607$ inc. $1^{\circ}$ ). El artículo 2205 del $C C$, en cambio, permite convenir intereses en dinero o en cosas fungibles.

${ }^{45}$ Es extraña la manera de hablar de este artículo: un convenio puede ser expreso, tácito o presunto; pero no decimos que se presume una convención tácita: si se presume, no es tácita; y si es tácita, no se presume. 
Ahora bien, en el caso $a$ ) y en el caso $b i i$ ) el depositario carga con todos los provechos y riesgos de la cosa; y se trata propiamente de un "dépôt irrégulier". En el caso $b$ i), el depositario no puede servirse del dinero encerrado o sellado y si lo hace, en todo caso debe indemnizar al depositante y, además, responderle por la pérdida fortuita del dinero, a menos de probar que el dinero igualmente se hubiera destruido aunque no se hubiese servido de él el depositario ${ }^{46}$.

En el segundo caso rigen las mismas reglas, pero la autorización para disponer de lo depositado debe ser concedida de manera expresa; y no cabe, pues, una autorización tácita ni una presunta.

i) Corresponde ahora que nos ocupemos del Codice Civile italiano de 1942. Trata de la materia en general ${ }^{47}$ su artículo 1782 :

"Deposito irregolare./Se il deposito ha per oggetto una quantità di danaro o di altre cose fungibili, con facoltà per il depositario di servirsene, questi ne acquista la proprietà ed è tenuto a restituirne altrettante della stessa specie e qualità./ In tal caso si osservano, in quanto applicabili, le norme relative al mutuo".
"Depósito irregular./ Si el depósito tiene por objeto una cantidad de dinero o de otras cosas fungibles, con facultad para servirse de ellas dada al depositario, éste adquiere su propiedad y queda obligado a restituir otra tanta cantidad de la misma especie y cualidad./ En tal caso se observan, en cuanto aplicables, las normas concernientes al mutuo".

La norma define los trazos esenciales del depósito irregular: la operación tiene por objetivo dinero u otras cosas fungibles; el depositario adquiere la propiedad de dichos objetos; y queda obligado a restituir otro tanto del mismo género y calidad. Pero ella incluye en su tipificación que haya facultad para servirse del dinero o los fungibles depositados, sin indicación de si aquella debe ser expresa o si puede ser tácita. Supuestos tales objetos y la mencionada facultad deben aplicarse las normas sobre el mutuo ${ }^{48}$.

${ }^{46} C C$ suiz., artículo 174: "1. Le dépositaire ne peut se servir de la chose sans la permission du déposant./ 2 S'il enfreint cette règle, il doit au déposant une juste indemnité, et il répond en outre du cas fortuit, à moins qu'il ne prouve que la chose eût été atteinte également s'il ne s'en était pas servi" ("El depositario no puedeservirse de la cosa sin permiso del depositante./ 2. Si enfrenta esta regla debe una justa indemnización al depositante y además responde del caso fortuito, a menos que pruebe que la cosa hubiera sido igualmente alcanzada si él no se hubiese servido de ella").

${ }^{47}$ Sobre el depósito irregular en el Derecho italiano: Delmartello - Portale (1964), $\mathrm{N}^{\circ}$ 31, pp. 269-272.

${ }^{48} \mathrm{El}$ artículo 1834 atañe al depósito de dinero en una banco: "Depositi di danaro./ Nei depositi di una somma di danaro presso una banca, questa ne acquista la proprietà ed è obbligata a restituirla nella stessa specie monetaria, alla scadenza del termine convenuto ovvero a richiesta del depositante, con l'osservanza del periodo di preavviso stabilito dalle parti o dagli usi./ Salvo patto contrario, i versamenti e i prelevamenti si eseguono alla sede 
j) En el libro II, tít. $2^{\circ}$, capítulo $11^{\circ}$ del Código Civil portugués de 1966 , hay una sección $5^{\mathrm{a}}$ rubricada: "Depósito irregular", que contiene dos artículos. El artículo 1205 dice:

"Noção./ Diz-se irregular o depósito que tem por objecto coisas fungíveis" ("Noción./ Dícese irregular el depósito que tiene por objeto cosas fungibles")

y el artículo 1206 expresa:

"Regime,/ Consideram-se aplicáveis ao depósito irregular, na medida do possível, as normas relativas ao contrato de mútuo" ("Régimen./ Considéranse aplicables al depósito irregular, en la medida de lo posible, las normas relativas al contrato de mutuo").

El concepto de depósito irregular ofrecido por la primera de las normas citadas, por su claridad y exactitud no exige comentarios. La segunda, en realidad tampoco.

k) Todavía queda por examinar el dispositivo del Código Civil de Brasil de 2002, cuyo artículo 645 reza así:

"O depósito de coisas fungíveis, em que o depositário se obrigue a restituir objetos do mesmo gênero, qualidade e quantidade, regularse-á pelo disposto acerca do mútuo" ("El depósito de cosas fungibles, en que el depositario se obligue a restituir objetos del mismo género, cualidad y cantidad, se regulará por lo dispuesto acerca del mutuo").

La norma supone que puede haber depósito de cosas fungibles en que el depositario no se obliguea restituir objetos del mismo género, cualidad y cantidad; pero deja completamente en suspenso el punto.

l) No tratan ni mencionan el depósito de dinero u otros fungibles los Códigos de México (1928), Quebec (1991/1994) y Holanda (1992).

2. Las líneas que se siguen de la presentación antecedente son estas:

a) Por regla general los códigos examinados aplican las reglas del mutuo al depósito de dinero o de otros fungibles, sea

della banca presso la quale si e costituito il rapporto" ("Depósito de dinero. En el depósito de una suma de dinero en un banco, éste adquiere su propiedad y queda obligado a restituirla en la misma especie monetaria al cumplirse el término convenido o bien a requerimiento del depositante con observancia del período de aviso previo establecido por las partes o por los usos./ Salvo pacto en contrario, los pagos y depósitos tienen lugar en la sede del banco en la cual se constituyó la relación”). Pasaremos por alto esta norma precisamente por consistir en un depósito irregular especial, cuya especialidad radica en ser un banco el depositario. El depósito de dinero en persona distinta a un banco se rige por el artículo $1782 C C$ it. antes transcrito. 
i) porque consideran que el negocio transita a mutuo [Baviera, v. 1 a)], Prusia [v. 1 b)], Austria [v. 1 d $)$ ], España [v. $1 f f]$;

ii) sea porque ordenan de modo directo tal aplicación sin preocuparse si el negocio sea mutuo o no [Alemania [v. 1 g)], Italia [v. 1 i)], Portugal [v. $1 j$ )] y Brasil [v. $1 k)]$.

El Código de Prusia [v. 1 b)] considera que el depósito de dinero $\mathrm{u}$ otros fungibles con autorización para tenerlas como si se las hubiera dado en mutuo, es un mutuo en fraude a la ley. El Código de Francia [v. 1 c)] considera que el depósito de dinero es un depósito normal (regular) y, por ende, ignora los efectos propios de la figura del llamado irregular

No asimilan el depósito irregular al mutuo pero reconocen su existencia y le imponen un régimen propio los Códigos de Argentina [v. 1e)] y Suiza [v. $1 h)]$,

Ignoran y no mencionan el depósito de dinero o fungibles los Códigos de México [v. 1 l)], Quebec [v. 1 l) y Holanda [v. 1 l)].

b) La idea de que el depósito de dinero u otros fungibles permite usar tales objetos debido a un permiso o una autorización dados expresa o tácitamente por el depositante al depositario es aceptada por los Códigos de Baviera [v. 1 a)], Prusia [v. 1 b)], Austria [v. 1 d)], España [v. $1 f f]$, Alemania [v. $1 g)$ ], Suiza v. 1 h)] e Italia [v. 1 i)].

Claramente prescinden de la idea de autorización para usar los fungibles o devolver el tantumdem los códigos de Argentina [v. 1 e)] y Portugal [v. 1 j]]; el de Brasil [v. 1 k)] deja ver cierta ambigüedad al respecto ${ }^{49}$.

c) Seis códigos usan el adjetivo 'irregular' para designar al depósito de dinero u otros fungibles, de los once examinados que describen la figura, con independencia del régimen que le impongan. Son los de Baviera [v. 1 a)], Argentina [v. 1 e)], de Alemania [v. $1 g)]$, de Suiza [v. $1 h)]$, Italia [v. $1 i)]$ y Portugal [v. $1 j)]$.

d) El único código que comprendió a cabalidad la naturaleza del depósito irregular ha sido el de Argentina [v. 1 e)] (ni siquiera el chileno, como veremos), porque, para considerar que haya depósito irregular, le basta exigir que el objeto depositado sea dinero o cierta cantidad de consumibles ${ }^{50}$ entregados al descubierto, vale decir, no en bultos sellados, o en sacos o cajas cerrados o en estas últimas cuya llave confía al depositario, haya o no el depositante concedido su uso al

${ }^{49}$ Porque habla de un depósito de fungibles en que el depositario se obligue a restituir objetos del mismo género, etc., y da a entender que podría no obligarse a tal y que, por ende, la restitución del tandumdem depende de la convención.

${ }^{50} \mathrm{Al}$ exigir "consumibles" ese cuerpo legal se equivoca, empero, porque basta una cantidad de fungibles, sean o no consumibles. 
depositario y, aunque se lo hubiera prohibido. El mero hecho de depositar fungibles en descubierto, pues, con independencia de la convención o la voluntad de las partes -como lo veremos dentro de poco-, constituye al depósito irregular; y son superfluas todas las prescripciones de los demás códigos en cuanto distingan si hubo autorización de uso o no la hubo, si la que hubo fue expresa o tácita, y dispongan que la mera entrega en descubierto constituye autorización tacita, etc. Particular reproche merece el Código francés [v. 1 c)] que, bajo la pretensión de negar existencia al depósito irregular, exige que el de monedas deba ser restituido en las mismas especies, porque eso está fuera del control del depositante y no es posible verificar.

\section{UN PRESUPUESTO DEL DEPÓSITO IRREGULAR}

1. La configuración del depósito irregular descansa sobre el presupuesto de un fenómeno jurídico que tiene lugar cuando fungibles o consumibles que "pertenecen" alguien pasan a la posesión de otra persona. Este "pasar a la posesión de otro" puede ser por hurto, por entrega a título traslaticio, como por venta, donación, permuta, pago, etcétera; o por entrega a un título no traslaticio 116 como por comodato, arrendamiento, prenda, depósito, usufructo, etcétera. Compárese cada situación con la respectiva que tiene lugar si la cosa de que se trata es un no fungible y no consumible, como una obra de arte por ejemplo.

Se tendrá presente que siempre suponemos que los fungibles y no consumibles de que hablamos no están guardados en un recipiente del que solo está consentido extraerlos si se lo rompe o fractura, porque en caso contrario, la infungibilidad e inconsumibilidad del continente infungibiliza y hace inconsumibles al contenido.

Sostenemos que, tratándose de cosas fungibles y consumibles, la tenencia se confunde con la posesión y esta con la propiedad. Pero nos limitaremos a razonar sobre la base de la tenencia, para evitar colisiones con el artículo 725 del $C C^{51}$. Si sostenemos, pues, que el tenedor de una cosa es su dueño, deberemos aceptar que cualquier cambio en la tenencia de tal cosa hace perder ese dominio, que es adquirido por el nuevo tenedor. Es como si en Chile valiera, mutatis mutandis, la máxima del Derecho francés: "En fait de muebles, posessión vauttitre" ${ }^{2}$, pero aplicada a los muebles fungibles y consumibles.

${ }^{51}$ Artículo 725 del $C C$ : "El poseedor conserva la posesión, aunque transfiera la tenencia de la cosa, dándola en arriendo, comodato, prenda, depósito, usufructo o a cualquiera otro título no translaticio de dominio".

52 Artículo 2.279 inc. $1^{\circ}$ del $C C$ fr. Sobre el alcance de esta regla, puede verse: Carbonnier (2004), Nos 889-891, pp. 1869-1871. 
La razón positiva de por qué aquello es así, deriva de que solo se pueden reivindicar cosas identificables. Tal, empero, no está dicho directamente en el Código Civil, debido, tal vez, a su evidencia. Pero se desprende de importantes disposiciones.

La primera es el artículo $2466 \operatorname{del} C C$ :

"Sobre las especies identificables que pertenezcan a otras personas por razón de dominio, y existan en poder del deudor insolvente, conservarán sus derechos los respectivos dueños, sin perjuicio de los derechos reales que sobre ellos competan al deudor, como usufructuario o prendario, o del derecho de retención que le concedan las leyes; en todos los cuales podrán subrogarse los acreedores".

La norma pertenece a la parte del título $41^{\circ}$ : "De la prelación de créditos". Esta prescribe varias cosas; pero todas descansan sobre la base de que entre los bienes de un deudor insolvente al que se pretende ejecutar, existan "especies identificables". Este modo de decir, equivale a "cosas infungibles", cuyo carácter radica precisamente en su identificabilidad. Si, pues, entre los bienes de un insolvente de encuentran infungibles ajenos, sus respectivos dueños siguen siendo tales, es decir, pueden reivindicarlos, sin perjuicio de que el insolvente sea su usufructuario, pignoratario o retencionario. Supongamos que se trate de objetos fungibles, o sea, inidentificables, y que un tercero alegue ser su dueño para sustraerlos a la ejecución. Si no es capaz de identificarlos, porque no puede, ¿cómo podría solicitar que se los apartara de la masa ejecutable? No hay que probar que tales bienes le pertenecen y toda prueba que se fabrique al respecto es necesariamente falsa.

Enseguida se presenta el artículo 2153 del $C C$ :

"Las especies metálicas que el mandatario tiene en su poder por cuenta del mandante, perecen para el mandatario aun por fuerza mayor o caso fortuito, salvo que estén contenidas en cajas o sacos cerrados y sellados sobre los cuales recaiga el accidente o la fuerza, o que por otros medios inequívocos pueda probarse incontestablemente la identidad".

La disposición está montada sobre el hecho de que un mandatario tenga en su poder "especies metálicas", o sea, dinero en la actual realidad monetaria $^{53}$, por cuenta de su mandante; y que se pierdan, sea por culpa o

${ }^{53}$ Pero no hay razón para fijar el alcance de la norma en el dinero, pues vale para cualquier otro fungible. 
dolo del mandatario o de un tercero, o por caso fortuito o fuerza mayor. La norma dice que en todo caso la pérdida es para el mandatario; con una excepción que el dinero haya llegado al mandatario y permanecido encerrado en cajas o sacos cerrados en sus manos, o "que por otros medios inequívocos pueda probarse incontestablemente la identidad". En este caso, en realidad, se trató de una cosa identificable, vale decir, de un infungible; y entonces la pérdida fortuita del continente con su contenido, grava al mandante. Como se ve, lo decisivo es el carácter identificable del dinero.

También comparece el artículo 2202 del $C C$ :

"Si hubiere prestado el que no tenía derecho de enajenar, se podrán reivindicar las especies, mientras conste su identidad./[Inciso $2^{\circ}$ ] Desapareciendo la identidad, el que las recibió de mala fe será obligado al pago inmediato con el máximum de los intereses que la ley permite estipular; pero el mutuario de buena fe sólo será obligado al pago con los intereses estipulados y después del término concedido en el artículo 2200".

La norma fue escrita en tema de mutuo; y dice que si un préstamo mutuo hubiese sido ejecutado por quien no tenía derecho de enajenar los fungibles que de hecho prestó, su verdadero dueño los puede reivindicar; pero añade: "mientras conste su identidad". Esto es lógico, porque los fungibles, confundidos con otros, no admiten ser separados para devolverlos a su "dueño". De hecho, la norma contiene un homenaje a la idea de dominio de unos fungibles, pero sin efecto; porque una de dos: o aquellos estaban identificados desde el principio o no lo estaban; en el primer caso, no hubo mutuo (art. 2196 del $C C$ ), porque lo prestado fue un infungible (por ejemplo, dinero encerrado en un arca, el trigo del silo $\mathrm{N}^{\circ} 5$, etcétera); en el segundo hubo mutuo, y no puede constar ninguna identidad de los fungibles prestados, por definición inidentificables. Las verdadera norma está en el segmento segundo: "Desapareciendo la identidad", en que se sanciona al mutuario de mala fe con el pago inmediato con el máximo de los intereses que la ley permite cobrar (se entiende que por el período completo en que tuvo los fungibles ajenos en su poder). La norma es, asimismo, más teórica que real: se supone que alguien prestó a otro fungibles ajenos y que el mutuario supo que eran ajenos los que recibió en préstamo ¿Cómo puedo alguien saber que unos infungibles recibidos de otro en préstamo no le pertenecen? Todavía podemos presentar al artículo 291 del $C P C$ :

"Habrá lugar al secuestro judicial en el caso del artículo 901 del Código Civil, o cuando se entablen otras acciones con relación a cosa mueble determinada y haya motivo de temer que se pierda o 
deteriore en manos de la persona que, sin ser poseedora de dicha cosa, la tenga en su poder".

El artículo 901 del $C C$ contiene la hipótesis de la reivindicación de una cosa corporal mueble con respecto a la cual haya motivo para temer su pérdida o deterioro en manos del poseedor. Esta norma, empero, no exige que el mueble sea identificable, determinado o cierto. Pero el artículo 291 del $C P C$, en el fondo, lo interpreta bien, cuando al extender la regla civil a otras acciones sobre cosa mueble, exige que se trate de "cosa mueble determinada", comprendiendo exactamente que, si no sea así, en realidad no podría haber una acción reivindicatoria.

Las normas examinadas dan el verdadero sentido de la ley: solo pueden ser reivindicadas las cosas infungibles o identificables; si no lo sean, no resulta posible que, en el conjunto de las existentes, sean señaladas por alguien para separarlas como propias a diferencia de las restantes, que son ajenas. Si son todas iguales, ¿cómo alguien podría ejecutar semejante operación discriminadora en un conjunto de cosas confundidas y no preidentificadas por algún signo exterior?

Cuando, en la realidad, los fungibles que estuvieron en el poder de uno, al que llamamos "dueño", pasan al de otro por hurto o un título no traslaticio de dominio, como por comodato, arrendamiento, prenda, depósito, usufructo, etcétera, el efecto no es, pues, la subsistencia de un "dominio" en favor del que dejó de tenerlos, sino sólo la adquisición de una acción personal para cobrarlos.

2. Sin embargo, la ley y los juristas suelen hablar de dominio de los fungibles. Tal lenguaje debe atribuirse una abusión o catacresis, que son las denominaciones atribuidas a un frecuente fenómeno lingüístico consistentes en que los hablantes apliquen a una cosa que carece de nombre propio el de otra por ser el más cercano disponible, como cuando se habla de las patas de una mesa o de los brazos de un sillón, pese a que las mesas no tienen patas ni los sillones, brazos. En el caso, la abusión radica en hablar de dominio o propiedad y de dueño de los fungibles, a semejanza de como se habla de dominio o propiedad y de dueño de los infungibles.

De acuerdo con lo dicho, cada vez que se celebra un acto jurídico recayente sobre fungibles con su tránsito de una parte a otra, en ningún caso el que los hace transitar puede ser considerado su dueño. Por lo que respecta a quien recibe los fungibles, en algunos casos empieza a deber su restitución, pero no los mismos individuos que recibió sino otro "tanto idéntico" (tantumdem), es decir, la misma cantidad de cosas de igual género y calidad al de las recibidas. Entretanto, puede tener, usar, disfrutar y disponer los individuos que recibió, lo cual permite catacréticamente sostener que es su dueño, pero solo mientras los tenga en su poder. 
3. La precedente discusión ofrece una importancia decisiva en la configuración del depósito irregular. Para que lo haya, entendiendo por tal la entrega de dinero o fungibles de modo expreso en depósito, ċacaso sea necesario autorizar el uso o disposición de los objetos al depositario, de modo que si no se diera tal autorización éste no podría usarlos o disponerlos? Y, ¿acaso sea necesario convenir de forma expresa que la propiedad de los fungibles depositados pase al depositario? La respuesta es negativa; es decir, la entrega de dinero o fungibles expresamente en depósito, permite sin más que el depositario use o disponga los objetos, porque ella lo convierte en su dueño. Más aún, ello fuere así aun en la hipótesis de que el depositante prohibiera el uso o la disposición de los fungibles al depositario; o que se conviniera en que su propiedad no transitara al depositario.

Como quedó dicho, ambas conclusiones son una aplicación de la doctrina sentada acerca de la propiedad de los fungibles. La entrega de estos a otro convierte a este en su "dueño" y le da el poder de usarlos y disponerlos. Como se trata de un depósito, empero, empieza a deber la restitución de otro tanto de cosas del mismo género y calidad; eso significa que las tiene acreditadas. El que entregó el dinero o los fungibles, aunque no haya dado su autorización de uso o consumo o, aunque hubiera pro120 hibido lo uno o lo otro, no tiene forma de impedir que el recipiendario se los apropie ni que, de hecho, los use o consuma y después restituya el tantumdem ${ }^{54}$.

La idea de que la configuración del depósito irregular exige la intervención de la voluntad de las partes remonta al glosador Accursius ${ }^{55}$. De su opinión más o menos conservada en la tradición posterior dependen siete de los once códigos que describen la figura del depósito de dinero $\mathrm{u}$ otros fungibles examinados en el capítulo IV, como son los de Baviera $[$ v. 1 a)], Prusia [v. 1 b)], Austria [v. 1 d $]$ ], España [v. $1 f$ )], Alemania [v. 1 $g)]$, Suiza v. 1 h)] e Italia [v. 1 i $]$ ].

${ }^{54}$ La idea opuesta, en orden a que el depósito irregular se configure merced a una expresa autorización de uso o disposición de los fungibles dada por el depositante, que también puede ser tácita y aun presunta (como se ve en tantos de los códigos antes examinados), arranca de una incorrecta interpretación de las fuentes romanas que hablan de autorización de uso, pero limitada al caso de la deposición de dinero especificado (que es regular), respecto del cual con posterioridad el depositante concede su uso al depositario, de modo de convertir el original depósito de un infungible en un mutuo de fungibles (véase la n. 18).

${ }^{55}$ Véase, más atrás, el capítulo IV, 1. 


\section{LA NATURALEZA Y EL RÉGIMEN DEL DEPÓSITO IRREGULAR}

1. El depósito irregular no es un depósito propiamente dicho ${ }^{56}$. El punto ya quedó introducido en la sección I de este trabajo. Ahí sostuvimos que el depósito propiamente dicho es un contrato consistente en la entrega de una cosa corporal mueble por un depositante a un depositario en función de guarda y custodia, y que este debe restituir al primero cuando le sea reclamada por el mismo. Dicho contrato es de mera tenencia, porque el depositario no adquiere el dominio de lo depositado, así que no puede usarlo, disfrutarlo ni disponerlo, y solo puede tenerlo. Pero si lo aplicamos a cosas fungibles resulta todo lo contrario: el depositario adquiere el dominio de los fungibles, los puede usar, disfrutar y disponer y no necesita conservarlos; solo debe el tantumdem. La lógica no resiste que resultados tan contradictorios sean producidos por una misma y única figura; así que el depósito irregular no puede ser un depósito ${ }^{57}$.

2. Hay una corriente, sin embargo, que sostiene lo opuesto y considera que el hecho de recaer sobre fungibles un depósito no hace mudar su naturaleza de tal; así que el depósito irregular es un auténtico y verdadero depósito.

a) Con todo, como la realidad no puede ser desconocida, los sostenedores de esta opinión se ven obligados a reconocer que la relación del depositario con la cosa es distinta en uno y otro caso: en el depósito regular se trata de un mero tenedor; en el irregular de un dueño (catacrético añadimos nosotros); así que mientras el depositario regular no puede disponer del objeto, el irregular sí.

Pero enseguida, para saldar un tanto la enorme diferencia que establece este reconocimiento, se añade que, en realidad, en el depósito irregular lo depositado no son las especies fungibles que transitan al depositario sino su cantidad y, en el caso de dinero, su valor. El depositario contrae la obligación de mantener a disposición del depositante la cantidad o los valores monetarios de que se trate, a fin de entregársela a su primer

${ }^{56}$ Micheo (1963) sostiene que el depósito irregular es un verdadero depósito, el cual, pues, ofrece dos especies: el regular y el irregular. Según él, el paso de la propiedad del dinero o de los fungibles depositados en un mero accidente, que no altera la esencia de la operación.

${ }^{57}$ Garrigues y Diaz-Cañábate (1932), Nº 93, pp. 654-656 y Nº 94, pp. 721-722, quien cree que el depósito irregular es un tipo de depósito, sostiene que la propiedad de los fungibles depositados no pasa al depositario y que la imposibilidad en que éste se encuentra de reivindicar lo suyo es solo debida a la falta de su individualización, lo cual no es signo de haber perdido la propiedad (pero cfr. lo que expresa en $\mathrm{N}^{\circ} 87$, p. 171). El autor dice basarse en COPPA-ZuCCARI (1901), pero no encontramos nada semejante ahí; por el contrario, véase lo que dice este último en pp. 153-154. 
requerimiento, no bien haya podido disponer de las especies individuales que recibió y devolver otras ${ }^{58}$. De esta manera su situación es semejante a la del depositario propiamente tal o regular, que ha de tener consigo la cosa para restituirla al depositante cuando la pida ${ }^{59}$. Una variante es que ni siquiera haya transferencia del dominio en el depósito irregular, porque el depositante lo mantiene sobre el tantumdem $^{60}$.

${ }^{58}$ No hace mucho (la $1^{\text {a }}$ edición del libro que se citará es de 1998, del cual en 2011 se ha tirado una $5^{\mathrm{a}}$ edición) esta teoría ha sido expuesta de manera precisa y extrema por el economista español Huerta de Soto (2009), capítulo $1^{\circ}$ : "Naturaleza jurídica del contrato de depósito irregular de dinero", pp. 9-34. Por ejemplo: "Sin embargo, hay que insistir en que la esencia del depósito sigue inalterada y en que el depósito irregular participa plenamente de la misma naturaleza esencial de todo depósito, que consiste en la obligación de guarda o custodia. En efecto, en el depósito irregular existe siempre una disponibilidad inmediata a favor del depositante que, en cualquier momento puede acudir al almacén de trigo, al depósito de aceite o a la caja del banco y retirare el equivalente de las unidades que originariamente entregó (pp. 12-13). Para ello, este autor opina: "La obligación de guarda y custodia que constituye el elemento esencial de todo depósito se concreta en el depósito irregular en una obligación de mantener siempre una completa disponibilidad del tantumdem en favor del depositante" (p. 13); y que esto: "en el caso concreto del bien fungible por excelencia, que es el dinero, significa que la obligación de custodia exige el mantenimiento en todo momento de un coeficiente de caja del 100 por 122 cien a disposición del depositante” (p. 14). En síntesis pues, el depositario, aunque pueda variar las especies, debe tener siempre dispuesto un tanto de las cosas del mismo género y calidad al de las recibidas (véase la p. 22 n. 20), con que restituir al depositante cuando lo pida. Si se trata de los bancos, su encaje debería ser del $100 \%$.

${ }^{59}$ En verdad, esta tesis ya había sido sostenida hace muchos años por COPPA-ZUCCARI (1901), pp. 95-97, aunque no con la claridad exhibida por el autor citado en la nota anterior.

${ }^{60}$ Huerta de Soto (2009), p. 12 n. 5: “otra solución [...] es la de considerar que en el depósito irregular no hay traslación verdadera de la propiedad, sino que esta viene referida en abstracto al tantumdem o cantidad de la cosa depositada y que, como tal, siempre permanece a favor del depositante y no se traslada. [...] aunque en el depósito irregular tradicionalmente se ha venido considerando otra cosa (el traslado efectivo de la propiedad sobre unas unidades físicas), parece más correcto admitir que la propiedad pueda definirse en los términos más abstractos del artículo 381 del Código Civil, en cuyo caso puede considerarse que no se produce traslación alguna de la misma cuando se efectúa un depósito irregular”. El artículo 381 del $C C$ esp. se refiere al caso de una conmixtión o mezcla de dos cosas de igual o diferente especie, decidida por sus dueños, o casual si las cosas no son separables sin detrimento, casos en los cuales "cada propietario adquirirá un derecho proporcional a la parte que le corresponda atendido el valor de las cosas mezcladas o confundidas". Lo que el Código establece es una comunidad, en la que cada anterior dueño singular tiene ahora un dominio pro parte indivisa. $\mathrm{O}$ sea, hay un cambio en la naturaleza del derecho de cada cual. El autor cree, en cambio, que cada uno tiene el mismo derecho de propiedad anterior, sobre el tantumdem y por analogía concluye que en el depósito irregular, el depositante conserva su dominio anterior sobre el tantumdem. Cfr. NetTelbladt (1785/1997), § 624, t. I, p. 259: “[...] depositum irregulare, si deposito adiectum pactum, quo depositario usus reie positae permittitur, siveillud pactum sitex pressum, sivetacitum; veluti si sola quantitas deposita” (“[...] depósito irregular, si al 
b) Esta doctrina no puede sostenerse en Chile. En rigor, ni siquiera es válida para el depósito regular. Es cierto que la ley afirma en la definición general del artículo 2211 del $C C$ que el depositario se encarga de guardar la cosa depositada, y en la especial del artículo 2215 del $C C$ que el depositante entrega un mueble para que el depositario lo guarde; y esto pudiere suscitar alguna opinión errada acerca del significado del verbo "guardar". Que el depositario esté encargado de "guardar" la cosa depositada en su poder no significa que tenga la obligación de hacer en orden a su "resguardo", "protección" o "salvaguardia" en el sentido, pues, de conservar, amparar y preservar la existencia e integridad física del cuerpo de que se trate, tomando precauciones para impedir su pérdida o deterioro ${ }^{61}$. Si así fuere, el depositario que se comportara de modo negligente con la cosa frente a los peligros que pudieron amenazarla aunque, con todo, la restituyere en el estado en que la recibió, incumpliría una obligación. Lo que por supuesto no es así. Supóngase que un depositario deja la obra de arte que le depositaron en el jardín de su casa colindante con la vía pública durante varios días; al cabo de los cuales el objeto es reclamado por el depositante, a quien se lo entrega de inmediato el depositario. Si la cosa es recibida por el depositante íntegra en devolución, no podría reclamar contra el custodio bajo el concepto de haber descuidado la cosa, por haberla dejado expuesta a que cualquiera que hubiera pasado por la calle pudo haberla tomado y llevado consigo o a que la intemperie la hubiera podido dañar. Ni siquiera en los casos de poder considerarse por completo doloso el comportamiento del depositario o de admitir la calificación de gravemente culposo estaría permitido juzgarlo si, pese a todo, restituyó íntegrala $\operatorname{cosa}^{62}$.

depósito se le añade un pacto, por el cual el uso de la cosa depositada es permitido al depositario, ora que el pacto sea expreso ora que tácito; como si se hubiera depositado solo la cantidad"), en donde parece percibirse que el autor considera que en el depósito irregular lo depositado es una cantidad. El error de todos estos razonamientos es confundir el accidente de la cantidad con la sustancia del ser al que se atribuye; como si la cantidad fuera una cosa sustancial en sí.

${ }^{61}$ De otra opinión OzCÁRIz Marco (1997), pp. 187-223

${ }^{62}$ Otra cosa es que el depositario responda normalmente hasta de la culpa grave (art. 2222 inc. $2^{\circ}$ del $C C$ ); porque eso solo significa poder exigirle una indemnización en el caso de perderse o deteriorarse la cosa debido a la falta de cierto cuidado que aun las personas negligentes y de poca prudencia suelen emplear en sus negocios propios (artículo 44 inc. $2^{\circ}$ del $(C)$ ), tanto como para merecer ese comportamiento su equiparación legal con uno doloso. Es, pues, el evento concreto de la pérdida o del deterioro de la cosa depositada el que desencadena esta responsabilidad, no el evento de haberse comportado sin un mínimo de cuidado, consistente en aquel que hasta los individuos negligentes y de escasa prudencia aplican en el cuidado de sus propias cosas. El depositario no tiene la obligación de salvaguardar la cosa, ni siquiera mínimamente, aunque responda por su pérdida o 
Cuando la ley emplea la voz 'guardar' en tema de depósito, pues, lo hacepara describir que por él la cosa se recibe solo tenerla sin uso ni goce, en oposición a cuanto acaece en el comodato, por el cual la cosa se recibe para hacer uso de ella (art. 2174 del $C$ C), en la prenda según la cual la recepción es en seguridad o garantía de un crédito (art. 2384 inc. $1^{\circ}$ del $C C$ ) o en el arrendamiento de cosas merced al que éstas son concedidas en uso y goce (art. 1915 del CC). Por consiguiente, al depositario no le queda más que "guardar" la cosa, esto es, instalarla, colocarla o dejarla en un lugar (que puede ser el interior de un objeto de moblaje, como en un cajón, estante, compartimento, etcétera), donde repose hasta que sea pedida por el depositante, sin usarla o gozarla en modo alguno ${ }^{63}$.

c) En tales condiciones, carece de sentido pretender que el depositario tiene alguna obligación de hacer antes de serle requerida la devolución de la cosa. Sobre tal base, también carece de sentido construirle una obligación a mantener de forma permanente en su poder -como petrificadoel tandumdem de fungibles depositados, que, aunque no la cumpliera el depositario, no habría como reprocharle ese incumplimiento si a última hora consigue devolverlo al depositante.

Otra cosa es que si, como inmediata respuesta al requerimiento de su devolución al depositante, no se los restituye el depositario. En tal caso 124 no interesa la causa de la no restitución que puede ir desde, en efecto, carecer del tantumdem hasta no querer pagarlo, pese a tenerlo disponible en sus arcas o en el banco. La ley no discrimina causas concernientes y, en la forma en que proceda, se limita a considerarlo en mora ${ }^{64}$, haya o no

deterioro si no la salvaguarda. Para el adecuado entendimiento de esta distinción, véase: BARros Bourie (2007), pp. 721-752.

${ }^{63}$ Interesa recordar que Windscheid (1887), § 377, p. 453 y n. 1, entendía el depósito como consistente en conceder un lugar al depositario para la deposición de la cosa. Obligarse además a alguna gestión con ella, como su salvaguardia, constituye un mandato, como se dice en Dig. 16,3,1,12 (Ulp., 30 ed.): "Quod si rem tibi dedi, ut [...] tu custodires [...] utrumdepositi tantum an et mandatiactiosit? Et Pomponiu dubitat; puto tamen mandatiesse actionem, quia pleniusfuit mandatum habens et custodiae legem" ("Pero si te di una cosa para [...] que tú la custodiaras [...], ċacaso habrá solo la acción del depósito o también la del mandato? Y Pomponio duda; mas yo pienso que se debe dar la acción del mandato, porque el mandato fue más completo y contiene también la cláusula de la custodia"). Como se observa, aquí se trata de determinar si el encargo de custodiar (o sea, de cuidar) está contenido en el depósito; y en la opinión de Ulpiano, tal encargo hace más bien parte de un mandato. No sabemos las razones de dudar de Pomponio.

${ }^{64}$ Se puede discutir si es aplicable el $\mathrm{N}^{\circ} 2$ o el $\mathrm{N}^{\circ} 3$ del artículo 1551 del $C C$ para constituir en mora al depositario La aplicabilidad del $\mathrm{N}^{\circ} 2$ es favorecida por la consideración de que, según la ley, el depositario debe restituir cuando el depositante le pida la cosa (arts. 2215 y 2226 del CC: "a voluntad del depositante"); y no carece de lógica ver que el requerimiento extrajudicial del depositante a partir del cual el depositario debe devolver sustituya el judicial del $\mathrm{N}^{\circ} 3$ del artículo 1551 del $C C$. 
tenido disponible el tantumdem. Esto sin hacer caudal de que la supuesta obligación de mantener de modo permanente a disposición el tantumdem haría inviable el depósito bancario de dinero, porque, obligados los bancos a ello, hubiera de ser el 100\% de los depósitos recibidos el que tendrían que mantener en bóveda, lo que, dicho sea de paso, haría innecesario el "encaje" bancario para los depósitos de dinero, que raramente llegan al $30 \%$.

3. El depósito de dinero u otros fungibles tampoco es un mutuo ${ }^{65}$; si lo fuera, el que entregó los fungibles no podría pedir su devolución cuando quisiera, sino al cabo de diez días al menos, en defecto de otro plazo mayor (art. $2201 \mathrm{del} C C$ ).

La verdadera naturaleza de la operación consiste en ser un crédito, sujeto, empero, a algunas reglas del depósito por voluntad de las partes, que quisieron que hubiera precisamente un depósito y no un mutuo. Esa voluntad fue suficiente para excluir a este último; pero no bastante para establecer un depósito, porque la naturaleza fungible de los objetos entregados impide generar los principales extremos que lo constituyen, a saber, que la propiedad de las cosas depositadas se mantenga en el depositante (si lo era o en el tercero cuyas eran), que el depositario adquiera su mera tenencia, que no deba disponer de ellas y que haya de restituir la misma especie recibida. Al revés, el depositario se hace "dueño" de los objetos recibidos en depósito cuya "propiedad" pierde correlativamente el depositante; aquel puede disponerlos; y solo debe restituir otro tanto del mismo género y calidad. Ahora bien, aunque esto recuerda al mutuo, no es un mutuo; el recuerdo es debido a que el depósito irregular asume el carácter de una figura más general que el mutuo, con la cual, sin embargo, guarda el mismo parentesco que hay entre el género y la especie; se trata del crédito ${ }^{66}$. Definimos al "crédito" como la dación en dominio de una cosa (corporal o incorporal, mueble o inmueble, fungible o infungible, consumible o inconsumibles) que obliga a quien la recibe a restituirla después al que se la dio; y esta definición por sí sola muestra cómo es que el crédito, constituyendo el género, no se confunde con una de sus especies, el mutuo y ni siquiera con otras como son los negocios irregular, entre los cuales está el depósito de dinero y otros fungibles.

4. El principal carácter crediticio del depósito irregular deriva de la obligación en que se encuentra el depositario de restituir otro tanto de cosas del mismo género y cualidad al depositante. Pero tal relación ser rige por las siguientes reglas del depósito:

${ }^{65}$ Como lo sostuvo Niemeyer (1888), p. 146. Para una adecuada discusión de las relaciones entre depósito y mutuo, véase Galassso (1976).

${ }^{66}$ Véase GuZmán Brito (en prensa). 
a) La del artículo 2216 inciso $1^{\circ}$ del $C C$ : el error sobre la identidad de cualquiera de las partes o acerca de la sustancia, calidad o cantidad de lo depositado, no invalida el contrato;

b) La del artículo 2216 inciso $2^{\circ}$ del $C C$ : el error acerca de la persona del depositante padecido por el depositario tampoco invalida el contrato, pero queda autorizada su revocación inmediata merced a la restitución de la cosa; y lo mismo acaece si el depositario o descubre que la guarda de la cosa le acarrea peligro;

c) La del artículo 2217: si el contrato debió otorgarse por escrito según las reglas generales, y se omitió tal formalidad, el depositario debe ser creído sobre su palabra, en orden al hecho mismo del depósito, en cuanto a la cosa depositada y al hecho de la restitución;

d) La del artículo 2218 del CC: la incapacidad del depositante no afecta a la integra validez de las obligaciones del depositario;

e) La del artículo 2219 del $C C$ : el depósito irregular es gratuito, en el sentido de no haber remuneración para el depositario;

f) Las del artículo 2225: si el depósito irregular es de confianza, el depositario no debe violar este secreto, ni podrá ser obligado a revelarlo.

g) Las de los artículos 2226 inciso $1^{\circ}$ y 2227 del $C C$ : la restitución del tantumdem de los fungibles depositados es a voluntad del depositante y la tenencia de la cosa debe durar hasta que éste la pida;

h) Las de los artículos 2226 inciso $2^{\circ}$ y 2227 del $C C$ : cuando se haya fijado un plazo para la restitución del tantumdem, tal cláusula solo obliga al depositario en cuanto no puede pretender devolverlo antes del plazo; llegado el cual podrá exigir el que depositante lo reciba(“disponga de ella" dice el art. 2227) o, en su defecto, consignarlo;

i) Las del artículo $2227 \mathrm{del} C C$ : el depositario puede exigir que el depositante reciba el tantumdem si las especies que han de integrarlo peligran en su poder o le causan perjuicio; en cuyo defecto, puede consignarlo;

j) La del artículo 2232: los costos de transporte necesarios para la restitución del tantumdem, si los hubiere, serán de cargo del depositante;

k) La del artículo 2234 del CC: el depositario no puede retener el pago del tantumdem para seguridad del pago de lo que el depositante le deba a él; lo impiden los artículos 2234 y 2182 (aplicable al depósito también irregular merced al art. 2233 del CC);

l) La del artículo 2235: el depositario no puede compensar la obligación de restituir el tantumdem con algún crédito suyo contra el depositante (a menos que éste consienta en la compensación); 
m) La del artículo 2235 del $C C$ : el depositante debe indemnizar al depositario los perjuicios que sin culpa suya (o sea, del depositante mismo) le hayan ocasionado los fungibles depositados.

n) Según el artículo 2235 del $C C$, se aplican al depósito las reglas de los artículos 2181 a 2185 del $C C$, dadas para el comodato; de ellas, reciben aplicación en el depósito irregular:

i) La del artículo 2181 del $C C$;

ii) La del artículo 2182: véase más atrás el $\mathrm{N}^{\mathrm{O}} 4 k$ );

iii) La del artículo 2185 del $C C$ : el depositario es dueño, desde su recepción, de los fungibles recibidos en depósito; y nunca puede restar en condiciones de probar que ellos le pertenecían antes de la recepción, de modo que le hubieran depositado cosa propia; así que la disposición es inaplicable al depósito irregular.

n) La norma del artículo $2184 \mathrm{del} C C$ es aplicable si se sabe que de los fungibles por restituir se haya de hacer un uso criminal, para ponerlos a disposición del juez. Tal sería el caso de unos fungibles consistentes en venenos o tóxicos, si se sabe que el depositante pudiera usarlos para ilícitos contra las personas o la población; o del dinero que se debe restituir a unos terroristas, que lo usarán para adquirir implementos para sus actividades criminales. La norma es lo suficientemente amplia como para comprender casos como estos.

o) La norma del artículo 2183 del $C C$ recibe una aplicación muy parcial al depósito irregular, porque nunca posible saber si los fungibles recibidos son los mismos que habían sido precedentemente hurtados, perdidos o robados y que después fueron depositados. La única hipótesis más o menos aplicable es la del segmento final del artículo 2183 inciso $1^{\circ}$ : "que se embargue judicialmente en manos de depositario", siempre que se entienda que lo embargado fue el crédito del depositante contra el depositario, cuyo objeto es la restitución del tantumdem, pues en tal caso el depositario debería suspender la restitución. No es posible pensar en que lo embargado al depositante hayan sido los fungibles depositados por él, porque perdió su dominio con el depósito.

5. Las normas que la ley da para el depósito y que no han sido citadas con anterioridad no son aplicables al depósito irregular por su propia naturaleza. Así:

a) La del artículo 2220 del CC: que atañe al uso de los infungibles regularmente depositados;

b) La del artículo 2222 del $C C$ : que se refiere al grado de culpa del depositario, inaplicable al depósito regular en el cual las cosas están a su riesgo; 
c) La de los artículos 2223 y 2224 del CC: inaplicables al depósito irregular que, por definición no puede recaer sobre cosas selladas ni encerradas;

d) La del artículo 2228 del CC: pues procede la excepción del artículo 221 ahí mismo enunciada;

e) La del artículo 2229 del $C C$ : pues las accesiones y los frutos de los fungibles depositados, si los hay, pertenecen al depositario, en su calidad de dueño de la cosa principal fructífera;

f) La del artículo 2230 del $C C$ : ya que en el depósito regular la fuerza mayor o caso fortuito gravan siempre al depositario;

g) La del artículo 2231 del CC: pues si los herederos del depositario venden los fungibles depositados, venden cosa propia, y el depositante nada más puede reclamarles que la restitución del tantumdem.

6. Por el contrario:

a) El depositario, puesto que se hace "dueño" de los fungibles que recibió en depósito, puede disponer de manera libre de ellos usándolos, disfrutándolos o consumiéndolos física o jurídicamente (art. 2221 del $C C$ );

b) Pero debe restituir el tantumdem al depositante cuando este se lo pida (artículo $2221 \mathrm{CC}$.);

128 c) Si los fungibles depositados perecen en concreto por fuerza mayor o caso fortuito, la pérdida o el riesgo es para el depositario;

d) En el mismo caso, no se extingue su obligación de restituir el tantumdem.

7. No son aplicables al depósito irregular, las siguientes reglas dadas por la ley para el mutuo:

a) La del artículo 2198 segmento $2^{\circ}$ : en el depósito irregular de fungibles que no sean dinero, no es posible reemplazar la devolución del tantumdem por el valor dinerario de lo que tales fungibles valgan en el tiempo y lugar en que ha debido hacerse el pago. La sustitución está prevista para el mutuo de fungibles que no sean dinero si el acreedor no exige que le sea devuelto el tantumdem o si tal devolución sea imposible; lo que no es aplicable al depósito de fungibles que no sean dinero, porque la combinación de los artículos 2228 y 2221 del $C C$ lo impide.

b) La del artículo 2200: los objetos deben devolverse al terminar el plazo fijado o, en el silencio de las partes, pasados los diez días subsiguientes a la entrega, porque priman los artículos 2215, 2226 y $2227 \mathrm{del} C C$ : la restitución debe tener lugar cuando el depositante la pida.

c) La del artículo 2221: en el depósito irregular no es posible pactar que depositario pague cuando le sea posible, de modo que pueda el juez, atendidas las circunstancias, fijar un término, porque el 
depósito irregular no funciona en beneficio del depositario. Un tal pacto fuere indicio seguro de que las partes quisieron celebrar un préstamo mutuo e incurrieron en el error de denominar depósito a la operación que ejecutaban.

d) La del artículo 2203 sobre perjuicios que sufra el mutuario por la mala calidad o los vicios ocultos de la cosa prestada, bajo las condiciones expresadas en el artículo 2192 del $C C$. Prima el dispositivo del artículo 2235 del $C C$, según el cual el depositante debe indemnizar al depositario de los perjuicios que sin culpa suya (o sea, del depositante mismo) le haya ocasionado el depósito, que es más amplio y menos restrictivo que el artículo 2203.

8. Las reglas que la ley $\mathrm{N}^{\circ} 18.010$ de 1981 impone a las operaciones de crédito de dinero son aplicables al depósito irregular de dinero, porque en él se plasma la figura definida por el artículo 1 de dicha ley, que define las operaciones de crédito de dinero como aquellas por las cuales una de las partes entrega una cantidad de dinero a otra que se obliga a pagarla en un momento distinto de aquel en que se celebra la convención. Por consiguiente, en el depósito irregular de dinero se puede pactar tanto un reajuste (artículo 3) como un interés lícito (artículo 8) y en caso de silencio sobre este último particular, se devengará, por mandato legal, un interés corriente calculado sobre el capital o sobre el capital reajustado en su caso (artículo 12).

9. El depositante de fungibles ejecuta un depósito y no un mutuo, porque en verdad tiene un interés en dejarlos en manos de un depositario, normalmente por razones de seguridad. Robert Pothier incorporó este elemento extrínseco y sicológico en la definición misma de nuestra figura:

"Le dépôt irrégulier est un contrat par lequel une personne qui a une somme d'argent, qu'ilcroit n'être pas en sûreté chez lui, la confie à un de ses amis [...]" ${ }^{\prime \prime}$.

Incluso, dejando a un lado que el depositario no tiene por qué ser amigo del depositante, aquel, pues, entiende que la operación es en su beneficio, y por eso toma la iniciativa de ejecutarla. Tratándose del mutuo, en cambio, cuando es gratuito, él cede en beneficio del mutuario y, por ello, quizá sea él quien toma la iniciativa de pedir el préstamo.

Pero no debemos prestar mucha atención a estas circunstancias externas de hecho. En el mutuo oneroso, la operación beneficia al mutuante tanto como al mutuario; y no es seguro que en el depósito irregular haya

${ }^{67}$ Pothier (1847), No 82, p. 154: "El depósito irregular es un contrato por el cual quien tiene una suma de dinero que no la cree estar segura en él, la confía a uno de sus amigos [...]".. 
siempre un interés solo en el depositante; de hecho, en el moderno depósito irregular masivo en los bancos, hay un claro interés que también asiste a estos.

\section{El DEPÓSITO DE DINERO EN BANCOS}

Los bancos suelen recibir dinero del público bajo el concepto de depósito de varias maneras; entre las principales

i) como depósito en cuenta corriente;

ii) como depósito en cuenta de ahorro a plazo;

iii) como depósito a plazo y

iv) como depósito a la vista ${ }^{68}$;

y aún hay otras. Por cierto reciben dinero del público a otros títulos, como para conferir una boleta de garantía; pero eso escapa a nuestro interés actual.

El depósito de dinero en cuenta corriente es un contrato principalmente regido por los artículos 1 a 9 del decreto con fuerza de ley $\mathrm{N}^{\circ} 707$ : "Ley sobre cuentas corrientes bancarias y cheques" (Diario Oficial de 7 de octubre de 1982), y para efectuar el cual los bancos están autorizados de 130 forma expresa y privativa por la ley ${ }^{69}$. El artículo 8 del citado DFL N 707 autoriza a los bancos para cobrar comisión ${ }^{70}$ y abonar intereses en las cuentas corrientes de acuerdo con las normas que dicte el Banco Central ${ }^{71}$.

En los depósitos de dinero en cuenta de ahorro a plazo, que siempre generan intereses, el retiro está prefijado de modo riguroso en un determi-

${ }^{68}$ Sobre los depósitos de dinero en bancos véase: Claro Solar (1935), pp. 37-53. Según el autor, demasiado influido por la doctrina civilística francesa de entonces, el depósito de dinero (sea en un banco o no) es un verdadero depósito.

${ }^{69} \mathrm{El}$ artículo $69 \mathrm{~N}^{\circ} 1$ del DFL N ${ }^{\circ}$ 3: "Ley general de bancos" (Diario Oficial de 19 de diciembre de 1997) autoriza a los bancos para ejecutar las operaciones de recibir depósitos y celebrar contratos de cuenta corriente; y su artículo 69 prohíbe a toda persona no autorizada por otra ley dedicarse al giro que corresponda a las empresas bancarias y, en especial, a captar o recibir en forma habitual dinero del público, ya sea en depósito, mutuo o en cualquiera otra forma.

${ }^{70}$ En aplicación del artículo 809 del CCom que da derecho a exigir una retribución por sus servicios al depositario.

${ }^{71}$ Véase el "Compendio de normas financieras" del Banco Central, G: "Cuentas corrientes", capítulo III, G, 1: "Pago de intereses en cuentas corrientes bancarias en moneda nacional". En realidad, las facultades del Banco Central son más amplias que las limitadas a fijar comisiones e intereses, porque el artículo $35 \mathrm{~N}^{\circ} 1$ de la ley $\mathrm{N}^{\circ} 18.840$ : "Orgánica constitucional del Banco Central” le da potestad para dictar las normas y condiciones a que se sujetarán las empresas bancarias, sociedades financieras y cooperativas de ahorro y crédito en la captación de fondos del público, ya sea como depósito, mutuo, participación, cesión o transferencia de efectos de comercio o en cualquiera otra forma. 
nado número de oportunidades al año ${ }^{72}$; y en aquellos a plazo, que también generan intereses, el plazo funciona contra el depositante, a despecho de la regla del artículo 2226 inciso $2^{\circ}$ del $C C$, porque es facultativo para la empresa bancaria acceder o no al retiro anticipado ${ }^{73}$. Otra forma es el depósito a la vista, que se complica por la intervención de un documento llamado "vale-vista" merced al cual se puede exigir la devolución o el pago; no genera intereses.

Ahora bien, en todos estos casos lo que hay es un depósito irregular, en que el banco es el depositario y los clientes sus depositantes. Con lo dicho basta para hacer ver la importancia social y económica que ofrece el depósito irregular.

\section{EL DEPÓSITO DE MERCADERÍAS}

\section{EN ALMACENES GENERALES DE DEPÓSITO}

El depósito de mercaderías en almacenes generales de depósito es ordinariamente regular. Aunque con bastante muy frecuencia lo que se deposita en tales almacenes sea en sí mismo fungible, el artículo $5 \mathrm{~N}^{\circ} 7$ de la ley $\mathrm{N}^{\circ}$ 18.690: sobre Almacenes generales de depósito (Diario Oficial de 2 de febrero de 1988) exige que el certificado de depósito deba indicar las marcas y demás indicaciones necesarias para determinar la identidad y el valor de las especies depositadas o, bien, las indicaciones que exija el reglamento para establecer las características y fijar el valor de esas mismas especies. Aun las mercaderías naturalmente fungibles, pues, deben empezar a ser identificadas, con lo cual, en realidad, empiezan a ser convencionalmente infungibles; y, como quedó dicho, regular su depósito.

Pero el artículo 26 de la ley citada dispone:

“[Inciso $1^{\circ}$ ] Previo acuerdo entre el depositante y el almacenista, podrá almacenarse a granel cualquier mercadería susceptible de tal modalidad de depósito/ [Inciso $2^{\circ}$ ] En estos casos, el almacenista queda obligado a devolver a quien corresponda mercaderías de iguales características y valor que las depositadas./ [Inciso $3^{\circ}$ ] $\mathrm{Si}$ el almacenista no tuviere tales mercaderías, podrá devolver otras de la misma especie y de la calidad más aproximada y abonará o deducirá la diferencia de valor que corresponda. En ambos casos

${ }^{72}$ Véase el "Compendio de normas financieras" del Banco Central, E: "Ahorro", capítulo III. E.1.

${ }^{73}$ Véase el "Compendio de normas financieras" del Banco Central, B: Normas sobre captaciones, intermediación financiera y otras operaciones, capítulo III. B.1,1. 
se procederá de acuerdo a las normas que sobre el particular determine el reglamento. Las dificultades que se susciten entre las partes con motivo de la aplicación de esta norma serán materia de arbitraje forzoso. [Inciso $4^{\circ}$ ] En estos depósitos, el almacenista responderá siempre por las pérdidas o deterioros ocasionados por fuerza mayor, caso fortuito o vicios propios de las especies depositadas".

La disposición discurre sobre la base de que lo depositado son mercaderías fungibles, que no se individualizan; lo cual indica con recurso a la expresión "a granel"74. De ello se sigue que el almacenista resulte obligado a devolver, no las mismas mercaderías depositadas, sino tan solo otras de iguales características y valor que aquellas (inc. $2^{\circ}$ ); y que el riesgo de las mercaderías corra a su cargo (inc. $4^{\circ}$ ), a diferencia de la regla general según la cual este responde de su pérdida o deterioro causados por culpa (o dolo: art. 22). El depósito ejecutado de acuerdo con estas normas es, pues, irregular.

\section{El DEPÓSITO IRREgUlaR Y LA QUIEbRA}

132

Puede acaecer que el depositante o el depositario irregulares entren en quiebra o, como se dice ahora, en un proceso de reorganización y liquidación de [patrimonios de] empresas o personas. En tales casos, es importante determinar el destino de los fungibles depositados irregularmente.

a) Cuando el proceso afecte al depositante, los fungibles que depositó en otro no pueden ingresar en el acervo deudor, como manda el artículo 2465 del $C C$, porque no son suyos; así que en ningún caso contribuirán a pagar sus deudas. Pero como el depositante es titular de un crédito contra el depositario, cuyo objeto es el tanto de cosas del mismo género y calidad que los de las depositadas, ese crédito sí que forma parte del acervo deudor y contribuye al pago de las deudas del depositante.

b) Si el proceso afectare al depositario, los fungibles que recibió en depósito (si aún los posee), puesto que son suyos, forman parte del acervo deudor y contribuyen al pago de sus deudas. Por el contrario, el depositario no puede invocar el artículo 2466 del $C C$ para pedir que se separe de la masa deudora los fungibles que depositó, como si fueran de su dominio, porque, no siendo

${ }^{74}$ Según el Diccionario de la Real Academia Española (2001), p. 1153, esta voz, de origen catalán, significa en segunda acepción: "un género, sin envase, sin empaquetadura". 
identificables, no son suyos. Pero como es titular de un crédito por el tanto de esos fungibles, contra el fallido, puede verificarlo y hacerse pago de él en la forma que le corresponda, como en el caso de cualquier otro crédito.

XI. El DEPÓSITO IRREgular

Y EL DELITO DE APROPIACIÓN INDEBIDA

El artículo 470 del CPen. tipifica un delito que se acostumbra a denominar “apropiación indebida”. La norma reza así:

"Las penas del artículo $467^{75}$ se aplicarán también:/ $1^{\circ}$ A los que en perjuicio de otro se apropiaren o distrajeren dinero, efectos o cualquiera otra cosa mueble que hubieran recibido en depósito, comisión o administración, o por otro título que produzca obligación de entregarlo o devolverlo".

Supuesto que el dinero (u otros fungibles) sean entregados al descubierto y no en un recipiente cerrado, o sea, que se trata de un verdadero depósito irregular, no se comete el delito del artículo $470 \mathrm{~N}^{\circ}$ del CPen. si el depositario no restituye el objeto de ese depósito cuando el depositante se lo pide. Con la entrega inicial de los fungibles, aquel se hace su dueño; en consecuencia, es imposible que después se tipifique el verbo rector 'apropiarse'. De hecho, en efecto, la "apropiación” tiene lugar en el momento de la entrega de los fungibles por el depositante y de su recepción por el depositario, en favor de este,y no puede, por ende, ser delictual porque ella constituye el negocio lícito del depósito irregular. Como, por otro lado, en este negocio el dinero o los fungibles se entregan sin una finalidad determinada, tampoco puede tipificarse el otro verbo rector usado por la norma, que es 'distraer', cuyo significado natural es dar a cierta cosa un destino o aplicación diferentes a aquellos autorizados por el título merced al cual se la recibióo ${ }^{76}$. Como en el depósito irregular no hay fijación de destino o aplicación de los fungibles entregados al depositario, es imposible que este los distraiga en el sentido indicado, de los cuales, por otro lado, es dueño y soberano, por ende, para darles el destino que le plazca.

${ }^{75}$ La referencia al artículo 467 remite a las penas del delito ahí tipificado consistente en defraudar a otro en la sustancia, cantidad o calidad de las cosas que le entregare en virtud de un título obligatorio, las cuales consisten en presidio menor y multas que se gradúan de acuerdo con el monto de la defraudación.

${ }^{76}$ Para esta formulación me inspiro en Etcheverry (1998), tomo III, p. 426. 
Concluimos, pues, con la doctrina penalística mayoritaria, por lo demás ${ }^{77}$, que el depósito irregular no da lugar a la comisión del delito de apropiación indebida. La no restitución de los fungibles a petición del depositante es el mero incumplimiento de una obligación civil, por el cual, según el moderno Derecho Internacional, no se puede imponer detención o cárcel ${ }^{78}$.

\section{BibLIOGRAFÍA}

ADAMs, Bertrand (1962). Haben die Römer "depositumirregulare" undDarlehenunterschieden? Studia et Documenta Historiae et Iuris, No 28. Roma.

Astuti, Guido (1964), "Deposito (storia)", en Enciclopedia del Diritto, Milano, Giuffrè.

Azo (1506/1966), Summa super Codicem, Pavia, B. et A. fratres de Rovellis, reimpresión en Corpus glossatorum iuris civilis, II, Augustae Taurinorum, Ex Officina Erasmiana.

Barros Bourie, Enrique (2007), "La diferencia entre 'estar obligado' y 'ser responsable' en el derecho de los contratos", en Hernán CoRRAL - María Sara Rodríguez (coords.), Estudios de derecho civil. Santiago: LexisNexis, tomo II: Jornadas Nacionales de Derecho Civil, Olmué, 2006.

Baudry-Lacantinerie, Gabriel - Albert Wahl (1907). Traité théorique et pratique de droit civil. De la société, du prêt, du dépôt. Paris: Sirey.

Bonifacio, Franco (1948). "Ricerche sul deposito irregolare in diritto romano". Bullettino dell'Istituto di Diritto Romano. $\mathrm{N}^{\circ}$ 49-50. Roma.

Brasiello, Ugo (1956). "Aspetti innovativi delle costituzioni imperiali, I: L'aspetto innovativo-interpretativo". Studi in onore di Pietro de Francisci. Milano: Giuffrè, tomo IV.

Butrigarius, Iacobus (1606), In priman et secundam veteris Digestipartem. Romae: Typis Lepidi Facii, reimpresion, en Opera iuridica rariora. Bologna: A. Forni, 1978, tomo XV.

Carbonnier, Jean (2004). Droit civil, $2^{\text {a }}$ ed. "Quadrigue”. Paris: Presses Universitaires de France, tome II: Les biens. Les obligations.

Claro Solar, Luis (1930/1992). Explicaciones de derecho civil chileno y comparado. Reimpresión. Santiago: Editorial Jurídica de Chile, tomo vi: Los bienes, 1.

Claro Solar, Luis (1935). "Del depósito de dinero y especialmente del depósito bancario". Revista de Derecho y Jurisprudencia. N 32/3-4. Santiago.

77 Una completa discusión sobre esta materia se ve en Cueto EtcheverRy (2005), pp. 317-329.

${ }^{78}$ Declaración americana de los derechos y deberes del hombre, artículo 24 inciso $2^{\circ}$; Pacto internacional de derechos civiles y políticos, artículo 11; Convención americana sobre derechos humanos ("Pacto de San José de Costa Rica"), artículo 7 N 7 . 
Cueto EtcheverRy, Germán (2005). El delito de apropiación indebida. Administración desleal. Una visión de la doctrina y jurisprudencia. Santiago: Ediciones Jurídicas de Santiago.

Churruca, Juan de (1991). "Die Gerichtsbarkeit der 'praefectus urbis' über die 'argentarii' im klassischen römischen Recht”. Zeitschrift der Savigny-Stiftung. $\mathrm{N}^{\circ}$ 108. rom. Abt.: Köln y otras.

Delmartello, Arturo - Giuseppe Portale (1964).“Deposito (diritto vigente)”, en Enciclopedia del Diritto. Milano: Giuffrè.

Diccionario de la Real Academia Española (2001), 22ª ed. Madrid: Espasa.

Domat, Jean (1735). Les lois civiles dans leur ordre naturel. Paris: Th. De Hansy.

Enneccerus, Ludwig (1950). Derecho de obligaciones, tomo II: Doctrina especial, $2^{\mathrm{a}}$ ed. de la traducción al castellano de la $35^{\mathrm{a}}$ ed. alemana. Barcelona: Bosch.

Etcheverry, Alfredo (1998). Derecho penal. Parte especial. $3^{\text {a }}$ ed. Santiago: Editorial Jurídica de Chile, tomo III.

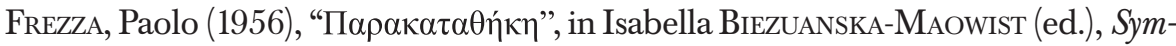
bolae Raphaeli Taubenschlag dedicatae. Vratislaviae - Varsaviae: Ossolineum, vol. I.

Galassso, Alfredo (1976). Mutuo e deposito irregolare. Milano: Giuffrè, I (único): La costituzione del rapporto.

GANDOLfi, Giuseppe (1976). Il deposito nella problematica della giurisprudenza romana. Milano:Giuffrè.

García Goyena, Florencio (1952). Concordancias, motivos y comentarios del Código Civil español. Madrid: Imprenta de la Sociedad Tipográfico-Editorial, tomo IV.

GaRRigues y Diaz-CAÑ́ÁBte, Joaquín (1932). "El depósito irregular y su aplicación en el derecho mercantil". Revista Crítica de Derecho Inmobiliario. $\mathrm{N}^{\circ} 86, \mathrm{~N}^{\circ} 87$, $\mathrm{N}^{\circ} 88, \mathrm{~N}^{\circ} 89, \mathrm{~N}^{\circ} 90, \mathrm{~N}^{\circ} 92, \mathrm{~N}^{\circ} 93$ y $\mathrm{N}^{\circ} 94$. Madrid.

Gordon, William Morrison (1982). "Observations on 'depositum irregulare", en Franco PAstori (ed.). Studi in onore di Arnaldo Biscardi. Milano: Istituto Editoriale Cisalpino - La Goliardica, tomo III.

Guzmán Brito, Alejandro (en prensa). "El concepto de crédito en el derecho chileno". Revista de Derecho de la Universidad Católica del Norte, Coquimbo.

HeIneccius, Johan Gottlieb (1773). Recitationes in elementa iuris civilissecundumordinemInstitutionum. Vratislavia: Imp. I. F. Kornius.

Herrera Bravo, Ramón (1987). El contrato de depósito en el derecho romano. Granada: [Universidad de Granada].

Huerta de Soto, Jesús (2009). Dinero, crédito bancario y ciclos económicos, 4ª ed., Madrid: Unión Editorial.

Klami, HannuTapani (1969). "Mutua magisvideturquam deposita". Über die Geldverwahrung im Denken der römischen Juristen. Helsinki: Akademische $\mathrm{Bu}-$ chhandlung.

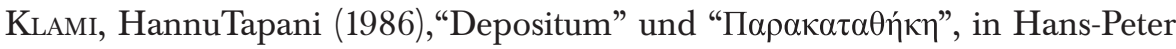
BENÖHR et al. (ed.). "Iuris professio". Festgabe für Max Kaser zum 80. Geburtstag. Wien: Böhlau. 
KRÜGER, Paul (1912). Geschichte der Quellen und Literatur des römischen Rechts. München: Duncker und Humblot.

KÜBLER, Bernhard (1908). "Griechische Tatbestände in den Werken der kasuistischen Literatur”. Zeitschrift der Savigny-Stiftung. Nº $^{\circ}$, rom. Abt.

Laurent, François (1893). Principes de droit civil. Bruxelles-Paris: Bruylant- Marescq, tome XXVII.

Litewski, Wieslaw (1974). "Le dépôt irrégulier". Revue Internationale des Droits de l'Antiquité. $\mathrm{N}^{\circ} 21$. Bruxelles.

Litewski, Wieslaw (1975). "Le dépôt irrégulier (II)". Revue Internationale des Droits de l'Antiquité. $\mathrm{N}^{\circ} 22$. Bruxelles.

Longo, Carlo (1906). "Appunti sul deposito irregolare". Bullettino dell'Istituto di Diritto Romano. No 18 . Roma.

Longo, Carlo (1964). Corso di diritto romano. Ildeposito. Milano: Giuffrè.

Martínez Gijón, José (1964). "La comenda en el derecho español, I: La comendadepósito". Anuario de Historia del Derecho Español, No 34. Madrid.

Michel, Jacques (1962). Gratuité en droit romain. Bruxelles: Université Libre de Bruxelles.

Micheo, Rafael (1963). "El depósito irregular". Revista de Derecho Privado, No 47. Madrid.

Mitteis, Ludwig (1898). "Trapezitika”. Zeitschrift der Savigny-Stiftung. No 19. rom.

136 Abt., Weimar.

NetTelbladt, Daniel (1785/1997). Systema elementare universae iurisprudentiae naturalis. $5^{\mathrm{a}}$ ed. Halae Magdeburgicae: In Officina Libraria Rengeriana. Reimpresión facsimilar Hildesheim y otras, Olms.

Niemeyer, Theodor (1888). "Depositumirregulare”. Halle: M. Niemeyer.

OzCÁRIZ Marco, Florencio (1997). El contrato de depósito. Estudio de la obligación de guarda. Barcelona: Bosch.

Petrucci, Aldo (1991). "Mensam exercere". Studi sull'impresa finanziaria romana. II secolo a.C - metà del III secolo d.C. Napoli: Jovene.

Planiol, Marcel - Georges RiPert (1954). Traité pratique de droit civil Français. Paris: Librairie Générales de Droit et de Jurisprudence, tome XI.

Polay, Elemér (1962). "Die Zeichen der Wechselwirkungen zwischen dem römischen Reichsrecht und dem Peregrinenrecht im Urkundenmaterial der siebenbürgischen Wachstafeln". Zeitschrift der Savigny-Stiftung. No 79. rom. Abt.

Pothier, Robert-Josepf (1847). Traite du contrat du dépôt, en CEuvres de Pothier, edición Bugnet. Paris: Videcoq - Cosse et Delamotte.

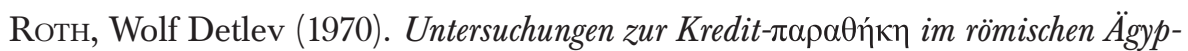
ten. Ein Beitrag zum Zinsrecht der Papyri und zum 'vó Dissertation. Marburg.

Santarelli, Umberto (1984/1990). La categoría dei contratti irregolari. Lezioni di storia del diritto. Reimpresión. Torino: Giappichelli. 
Schmoeckel, Mathias y otros (eds.) (2013). Historisch-kritischer Kommentar zum BGB, III: Schuldrecht. Besonderer Teilband, 2: §§ 657-853. Tübingen: Mohr Siebeck.

SEgRE, Gino (1907). "Sul deposito irregolare in diritto romano". Bullettino dell'Istituto di Diritto Romano. ${ }^{\circ}$ 19. Roma.

SEIDL, Erwin (1951). "Der Eigentumsübergang beim Darlehen und 'depositum irregular", en Hans Niedermeyer - Werner Flume (eds.). Festschrift für Fritz Schulz, Weimar: Böhlau. vol. I.

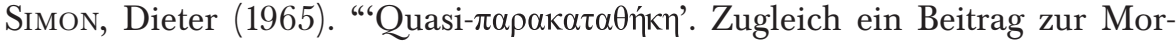
pholögie griechisch-hellenistischer Schuldrechtstatbestände". Zeitschrift der Savigny-Stiftung. N ${ }^{0}$ 82. rom Abt.,Köln y otras.

Simone, Mario de (1952/1993). I negozii irregolari. Napoli: Jovene. Reimpresión Università di Camerino, Camerino. Traducción española (1956). Madrid: Revista de Derecho Privado.

Troplong, Raymond-Théodore (1845). Le droit civil expliqué suivant l'ordre des articles du Code: Du dépôt et du séquestre et les contrats aléatoires. Paris: Ch. Hingray.

ValmañaOchaíta, Alicia (1996). El depósito irregular en la jurisprudencia romana, Madrid: EDISOFER.

VigneRon, Roger (1984). "Résistance du droit romain aux influences hellénistiques: le cas du dépôt irrégulier". Revue Internationale des Droits de l'Antiquité, $\mathrm{N}^{\circ} 31$. Bruxelles.

Windscheid, Bernard (1887). Lehrbuch des Pandektenrechts. $6^{\mathrm{a}}$ ed. Frankfurt am Main: Rütten \& Loening.

Wolf, Christian (1744). Ius naturae methodo scientifica pertractatum. Hallae Magdeburgicae: In Officina Libraria Rengeriana.

Wolf, Christian (1763). Institutiones iuris naturae et gentium. Hallae Magdeburgicae: In Officina Libraria Rengeriana. 